APAE Memo No. 260

Copy No.

\title{
SPECIFICATIONS AND FABRICATION PROCEDURES FOR PM-2A CORE II CONTROL ROD FUEL ELEMENTS
}

Materials Technology Branch

Nuclear Power Engineering Department

Issued: May 13, 1960

Contract No, AT(30-3)-326

With U. S. Atomic Energy Commission New York Operations Office

\footnotetext{
ALCO PRODUCTS, INC. Post Office Box 414

Schenectady i, New York
} 


\section{DISCLAIMER}

This report was prepared as an account of work sponsored by an agency of the United States Government. Neither the United States Government nor any agency Thereot, nor any of their employees, makes any warranty, express or implied, or assumes any legal liability or responsibility for the accuracy, completeness, or usefulness of any information, apparatus, product, or process disclosed, or represents that its use would not infringe privately owned rights. Reference herein to any specific commercial product, process, or service by trade name, trademark, manufacturer, or otherwise does not necessarily constitute or imply its endorsement, recommendation, or favoring by the United States Government or any agency thereof. The views and opinions of authors expressed herein do not necessarlly state or reflect those of the United States Government or any agency thereof. 


\section{DISCLAIMER}

Portions of this document may be illegible in electronic image products. Images are produced from the best available original document. 
AEC LEGAL NOTICE

This report was prepared as an account of Government sponsored work. Neither the United States, nor the Commission, nor any person acting on behalf of the Commission:

A. Makes any warranty or representation, expressed or implied, with respect to the accuracy, completeness, or usefulness of the information contained in this report, or that the use of any information, apparatus, method, or process disclosed in this report may not infringe privately owned rights: or

B. Assumes any liabilities with respect to the use of, or for damages resulting from the use of any information, apparatus, method, or process disclosed in this report.

As used in the above, "person acting on behalf of the Commission" includes any employee or contractor of the Commission, or employee of such contractor, to the extent that such employee or contractor of the Commission, or employee of such contractor prepares, disseminates, or provides access to, any information pursuant to his employment or contract with the Commission, or his employment with such contractor.

\section{ALCO LEGAL NOTICE}

This report was prepared by Alco Products, Incorporated in the course of work under, or in connection with, Contract No. AT(30-3)-326, issued by U.S. Atomic Energy Commlssion, New York Operations Office and subject only to the rights of the United States, under the provisions of this contract, Alco Products, Incorporated makes no warranty or representation, express or implied, and shall have no liability with respect to this report or any of its contents or with respect to the use thereof or with respect to whether any such use will infringe the rights of others. 


\section{DISTRIBUTION}

COPIES

$1-3$

New York Operations Office

U. S. Atomic Energy Commission

376 Hudson Street

New York 14, New York

Attention: Chief, Army Reactors Branch, NYOO

4-6 U. S. Atomic Energy Commission

Army Reactors Branch

Division of Reactor Development

Washington 25, D. C.

Attention: Chief, Water Systems Project Branch

Office, Ass't. Director (Army Reactors)

U. S. Atomic Energy Commission

Chief, Patents Branch

Washington 25, D. C.

Attention: Roland A. Anderson

8

U. S. Atomic Energy Commission

Chief, New York Patent Group

Brookhaven National Laboratory

Upton, New York

Attention: Harman Potter

9

Chief of Evaluation Planning Branch

Civilian Reactors

U. S. Atomic Energy Commission

Washington 25, D。C.

$10-11$

Nuclear Power Field Office

USERDL

Fort Belvoir, Virginta

Attention: Chief, Nuclear Power Field Office

at

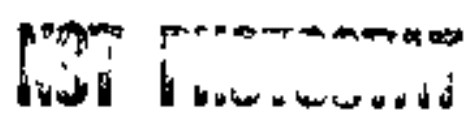


COPIES

12-13

Union Carbide Nuclear Corporation

Oak Ridge National Laboratory

Y-12 Building 9704-1

P. O. BoX "Y'"

Oak Ridge, Tennessee

Attention: A. L。 Boch

14

U. S. Atomic Energy Commission

Reference Branch

Technical Information Services Extension

P. O. Box 62

Oak Ridge, Tennessee

$15-16$

Sylvania Corning Nuclear Corporation

Bayside, Long Island,

New York

Attention: Mr. L. Smiley

$17-18$

Metals \& Control

Nuclear Division

Attleboro, Massachusetts

Attention: Mr. J. Williams

$19-20$

General Electric Company

San Jose, California

Attention: $\mathbf{M r}$ 。 G。 E. Richards

8 Colvin Avenue

Albany 1, New York

21-22

National Lead Company

Nuclear Power Division

Albany, New York

Attention: Mr. J. Farr

23-24

D. E. Makepeace Company

Division of Union Plate \& Wire Company

Attelboro, Massachusetts

Attention: Mr, J. H. Durant

iv 


\section{DISTRIBUTION (Cont ${ }^{*} \mathrm{~d}$ )}

COPIES

25-26

Curtiss-Wright Corporation

Quehanna, Pennsylvania

Attention: Mr, C. Leyse

27-28

Martin Company

Nuclear Division

Baltimore, Maryland

Attention: Mr. F。 J, Perella

$29-30$

Combustion Engineering, Incorporated

Prospect Hill Road

Windsor, Connecticut

Attention: Mr。 A. F。 Miller

31-32

Westinghouse Electric Company

19 Railroad Avenue

Albany, New York

Attention: Mr. R. Purdy

$33-34$

Olin-Mattheson Corporation

New Haven, Connecticut

Attention: Mr. D. Seth

Battelle Memorial Institute 505 King A venue Columbus, Ohio

Attention: S. Paprock1

Dr. R. L. Murray

North Carolina State College

P. O. Box 5596

State College Station

Raleigh, North Carolina

E. B. Gunyou

42

D. D. Foley

R, D. Robertson

39

40

41
A. Marimpietri

R. A. Shaw
E. C. Edgar

R. Kellerman

A. Wilder

File 
TABLE OF CONTENTS

Page

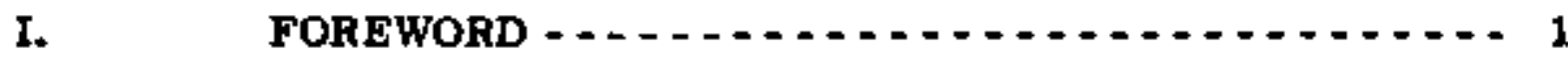

II. ABSTRACT $\ldots \ldots \ldots \ldots$

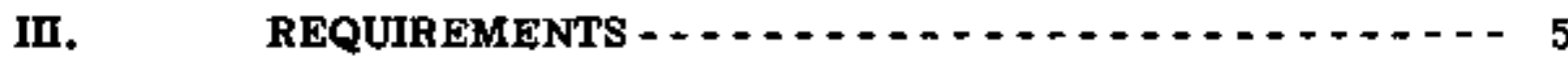

A. Adherence to Specifications - - $-\cdots-\ldots-5$

B. Special Precautions $\ldots \ldots \ldots \ldots \ldots$

1. Bonding $\ldots \ldots \ldots \ldots \ldots \ldots \ldots$

2. Fuel and Poison Distribution $-\ldots \ldots$

3. Cladding and Core $\ldots \ldots \ldots \ldots \ldots$

4. Materials - .......

5. Core Capsulating and Inspection -...... 6

C. Consistent Product Manufacture - - - - - - - - 6

D. Supervision and Control of Process - $\ldots \ldots \ldots$

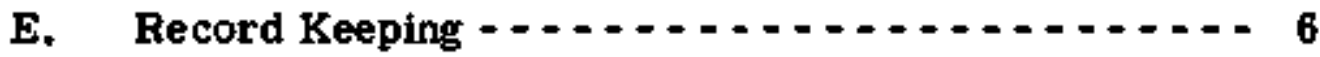

F. Product Identification - - - -

G. Processing Materials $\ldots \ldots \ldots \ldots$

IV. QUALIFICATION OF FABRICATION PROCEDURE AND QUALITY CONTROL $\ldots \ldots \ldots \ldots \ldots$

v. CORE LOADING SPECIFICATIONS AND A LIST OF

DRAWINGS - $\ldots \ldots \ldots$

VI. PROCESS AND MATERIALS SPECIFICATIONS $-\cdots-\cdots$

VII. GUIDE FORMS FOR, RECORDS -

vIII. SAMPLE CALCULATIONS - $\ldots \ldots$

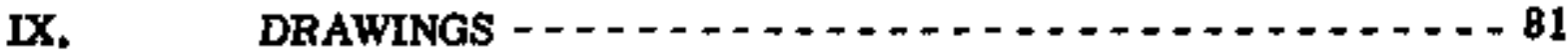




\section{'LIST OF ILLUSTRATIONS AND DRAWINGS}

Page

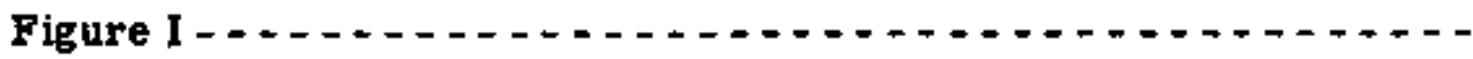

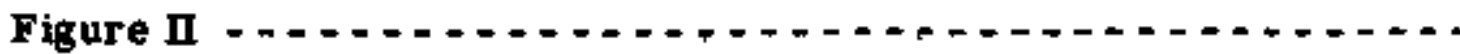

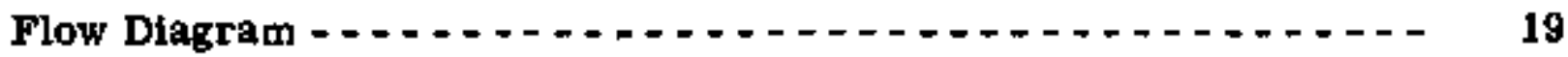

Powder Metallurgy Core Order Form - $\ldots \ldots \ldots \ldots \ldots$

Powder Metallurgy Core Order Form $\ldots \ldots \ldots \ldots \ldots$

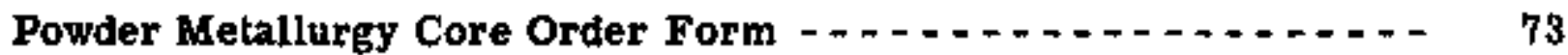

Powder Metallurgy Fabrication Form -

Rolling Schedule -

Fuel Plate Fabrication Record $\ldots \ldots \ldots$

Inspection Record - - $\ldots \ldots, 77$

Radiographic Inspection Sheet of Fuel Plates- $\ldots+\ldots$

Drawings

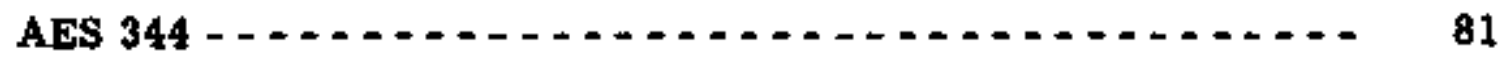

D9-13-1030--

D9-13-2149 and D9-13-2194-1

D9-13-2155 and D9-13-2155-1 $\ldots \ldots \ldots$

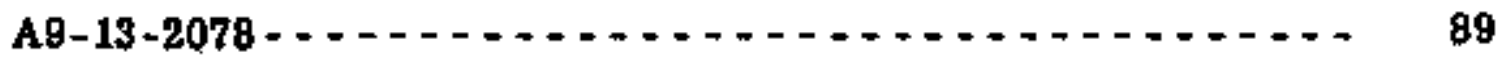

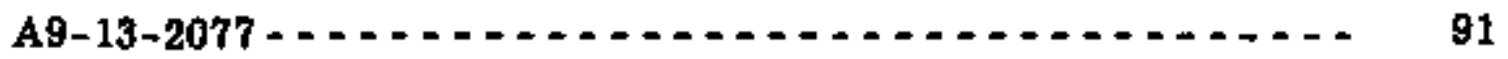




\section{FOR EWORD}

These specifications were prepared to aid in the procurement of control rod fuel elements for the Core II of PM-2A from an industrial fuel element manufacturer.

The material contained in these specifications is based on ORNL-2726 and ORNL-2649, Oak Ridge National Laboratory, Oak Ridge, Tennessee, and experience gained in the manufacture of simllar dispersion type stainless steel fuel elements, 


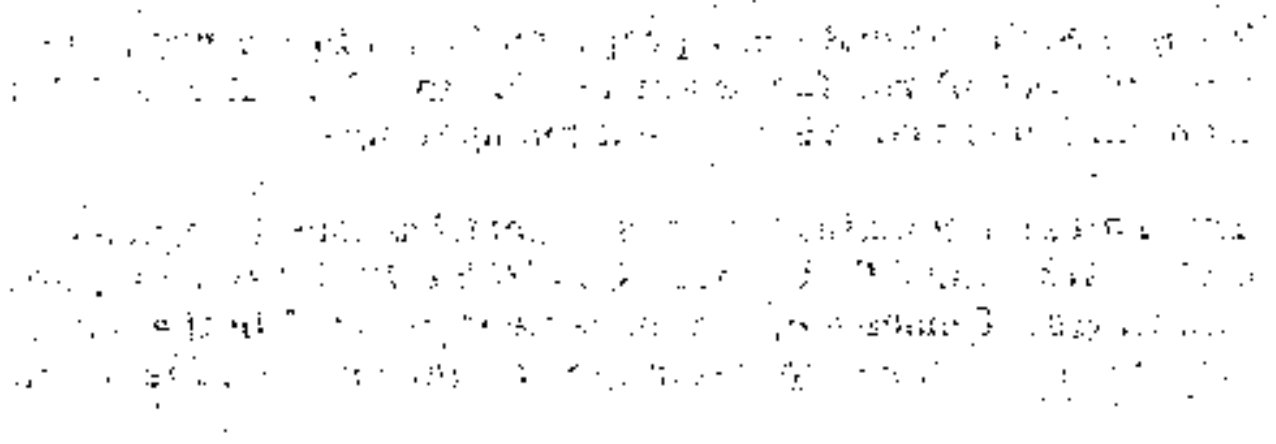




\section{ABSTRACT}

Stainless steel-base fuel components of thin plate-type construction and containing a dispersion of $\mathrm{UO}_{2}$ have been successtully employed in powering the Army Package Power Reactor. The component is designed for radioactive service in pressurized water and consists of sixteen composite fuel plates joined into an integral unit or assembly by brazing. Specifications covering loading, materials, and processing are presented. A list of applicable drawings and the process flow diagram are included. 


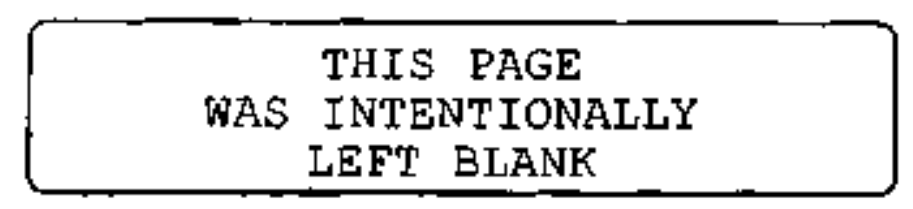

WAS INTENTIONALLY 


\section{REQUIREMENTS}

A. The fuel component is designed for radioactive service in pressurized water and once placed in operatton cannot be subjected to maintenance, repair or salvage:- It is imperative, therefore, that only the highest degree of quality obtainable with respect to materials of construction and workmanship be incorporated into the finished component. Hence, the component must be manufactured in strict accordance with the spectfications and process flow diagram.

B. Satisfactory performance of the reactor and of the fuel components during their operating life requires that special precautions be taken to insure the following:

1. A continuous metallurgical bond between clad and core matrix matertal must be obtained to insure proper heat removal and freedom from potential blisters which may rupture and release fission products to the coolant.

2. Uniform distribution of the fuel, burnable poison and flux suppressant in the core of the composite plate must be achieved. Heterogeneity of these important ingredients could lead to hot spots and ultimate failure by melting. To serve as a guide, sample loading calculations are furnished in Section VIII.

3. Uniformity in thickness of clad and core material must be maintained to insure protection from corrosion by the coolant and to achieve the required concentration of fuel in terms of grams of $\mathrm{U}-235 / \mathrm{cm}^{2}$ over the entire area of the active portion of the fuel plate.

4. The composition and processing of material must be controlled to minimize the presence of contaminants which may (a) accelerate corrosion, (b) contribute to parasitic absorption of neutrons, (c) reduce mechanical integrity of the fuel elements, (d) release gases which could promote swelling or blistering and ultimate rupture of the cladding, or (e) contaminate the surfaces of the fuel elements with traces of fissionable or fertile material that would increase the level of radioactivity in the coolant.

5. The various steps of framing, cladding, shearing, machining and brazing must be carried out and inspected in a manner to preclude the presence of fissionable material at the clad-frame interface as well as to insure that no portion of the fuel bearing core is exposed to the coolant. 
C. Fuel element manufacturing experience has demonstrated the feasibility of fabricating components which consistently meet the product standards required. Substantial assurance that the component meets these standards cannot be accomplished by nondestructive testing of random or control'samples. Instead these must be combined with the establishment of and rigid adherence to proven fabrication procedures, materials inspection and cleanliness standards. Industrial utilization of the processing procedures presented does not relieve a manufacturer from any'responsibility associated with the fabrication of a satisfactory product.

D. Sufficient and proper supervisory and production control must be provided by a manufacturer: (1) to insure that all detalls of the fabrication procedure conform at all times with the approved procedure, (2) to maintain rigid adherence to all specification requirements, (3) to protect personnel against human intake of airborne activity from alpha-emitting $\mathrm{UO}_{2}$ by inhalation or ingestion and to comply with the requirements of the International Commision on Radiation Protection, (4) to enforce safety measures to prevent a criticality incident, and (5) to safeguard and account for all fissionable material in accordance with the Atomic Energy Commission licensing agreement, or other arrangements with the A. E. C., as defined under the Atomic Energy Act.

E. It will be necessary to maintain sufficient and proper records to supply pertinent data required in the fabrication of the fuel elements. During processing, positive identification of each fuel plate must be maintained along with appropriate data in order to insure: (1) proper process control, (2) inspection and quality control, (9) metallurgical history record, (4) removal of rejected material, and (5) fuel and burnable poison accountability. Records of the following items shall be maintained and copies furnished to the Contracting Agency or its authorized representative with the finished fuel elements: (1) identification of each lot of $\mathrm{UO}_{2}$ received, (2) master log containing materials make-up and the detailed processing schedule employed in the manufacturing of each plate, (3) fuel element inspection card of critical dimensions.

To serve as a guide, the forms of the pertinent records are furnished in Section VII.

F. In addition to the identification numbers specified in the process specifications for components and fuel elements, a symbol indicative of the manufacturer shall be added to the end support or handle on each fuel element.

G. Care must be exercised in utilizing materials such as electrodes, filler rod, cleaning agents, and lubricants that come in contact with the product during processing. Pickling of the fuel plate in any solution containing a halide ion or reducing in nature shall not be allowed subsequent to 
removal of the scale from the hot rolled fuel plates. The use of any processing agent that may have a deleterious effect on the finished product is prohlbited. 
THIS PAGE

WAS INTENTIONALIY

LEFT BLANK 


\section{QUALIFICATION OF FABRICATION PROCEDURE}

1. Introduction

Quality control of the fuel elements is primarily attained by rigid adherence to proven fabrication procedures. Thus, specifications for the control rod fuel elements cannot be prepared along the lines normally used for industrial products, in which quality is assured by nondestructive inspection to industry-wide standards. Consequently, the fuel element manifacturer will be required to qualify the fabrication procedure which is to be employed in the fabrication of the fuel elements. The requirements specified for the qualification fuel plates and fuel elements shall also apply to the enriched fuel plates and fuel elements.

2. Method of Qualification

Qualifications shall be performed by subjecting fourteen sample fuel plates to the test outlined in Part 4 of this section. Approval of qualification shall be given by the Contracting Agency or its authorized representative when it has been demonstrated to the satisfaction of the Contracting Agency or its authorized representative that the requirements of Part 4 have been met.

3. Preparation of Qualification Samples

The fourteen fuel plates shall be prepared in conformance with the exact and complete fabrication procedure which is proposed to be used in the manufacture of the fuel elements, and in accordance with dimensional requirements specified for long fuel plates. Depleted uranium oxide, identical in every respect with the material to be used in the fuel elements, except in enrichment, shall be used in the sample fuel plates. The sample fuel plates shall be subjected to the maximum number of exactly duplicated high-temperature treatments which will be encountered in the proposed procedure for fabrication of completed fuel elements: Approval must be obtained prior to inception of manufacture of enriched fuel plates unless otherwise specifically authorized by the Contracting Agency or its authorized representative. Approval by the Contracting Agency or its authorized representative of the procedure as used in establishing qualification or of any modtfication thereof will not relieve the manufacturer of any responsibility for any phase of the fabrication of the fuel elements or for conformity to specification requirements.

The chemical analysis of qualification plates shall be performed only by a laboratory which has satisfactorily demonstrated its ability to analyze for 


$$
\text { europium }
$$

uraniumjand boron content of stainless steel dispersion type fuel plates. Choice of a laboratory for chemical analysis work shall be approved by the Contracting Agency or its authorized representative.

\section{Tests for Qualification}

\section{a. Visual Inspection}

Fourteen of the sample fuel plates shall be inspected for over-all width, length, and thickness dimensions and shall be inspected for pitting, surface conditions and finish. The fourteen sample fuel plates shall meet all dimensional requirements and-shall not exhibit any oxide indentations or pits over 0.001 inch deep, scratches over 0.001 inch deep, dents over the core area, blisters, scale, or surface discoloration.

\section{b. X-Ray Examination}

The fourteen sample fuel plates shall then be X-rayed to delineate the core area and to reveal any segregation and voids or other internal defects. The radiographs shall be made using proper techniques with a fine-grained film such as Eastman ' $M$ ", exposed and processed to yield a gamma density of 1.0-1.25 over the core area. The radiographs shall be used as the basis of measuring core length, core width, and inactive edges and ends.

The samples shall meet all dimensional requirements and shall exhibit no evidence of fuel segregation, voids or other internal defects.

\section{c. Surface Contamination}

The fourteen sample fuel plates shall all be checked for evidence of alpha contamination by means of gas flow proportional counting or a similar approved method. Alpha contamination equivalent to 0.5 micrograms of Uranium-235 per square foot of plate surface shall be the maximum allowable level of contamination. It is assumed that one microgram of Uranium-235 per square foot of surface of the fuel plate is equivalent to $\mathbf{1 5 0}$ disintegrations per minute per square foot of plate surface.

\section{d. Homogeneity}

If the fourteen sample fuel plates exhibit satisfactory homogeneity as evidenced by examination of the X-ray films, two of the fourteen shall be further examined. Five miniature samples of full-plate thickness approximately one-square inch in area shall be sheared 


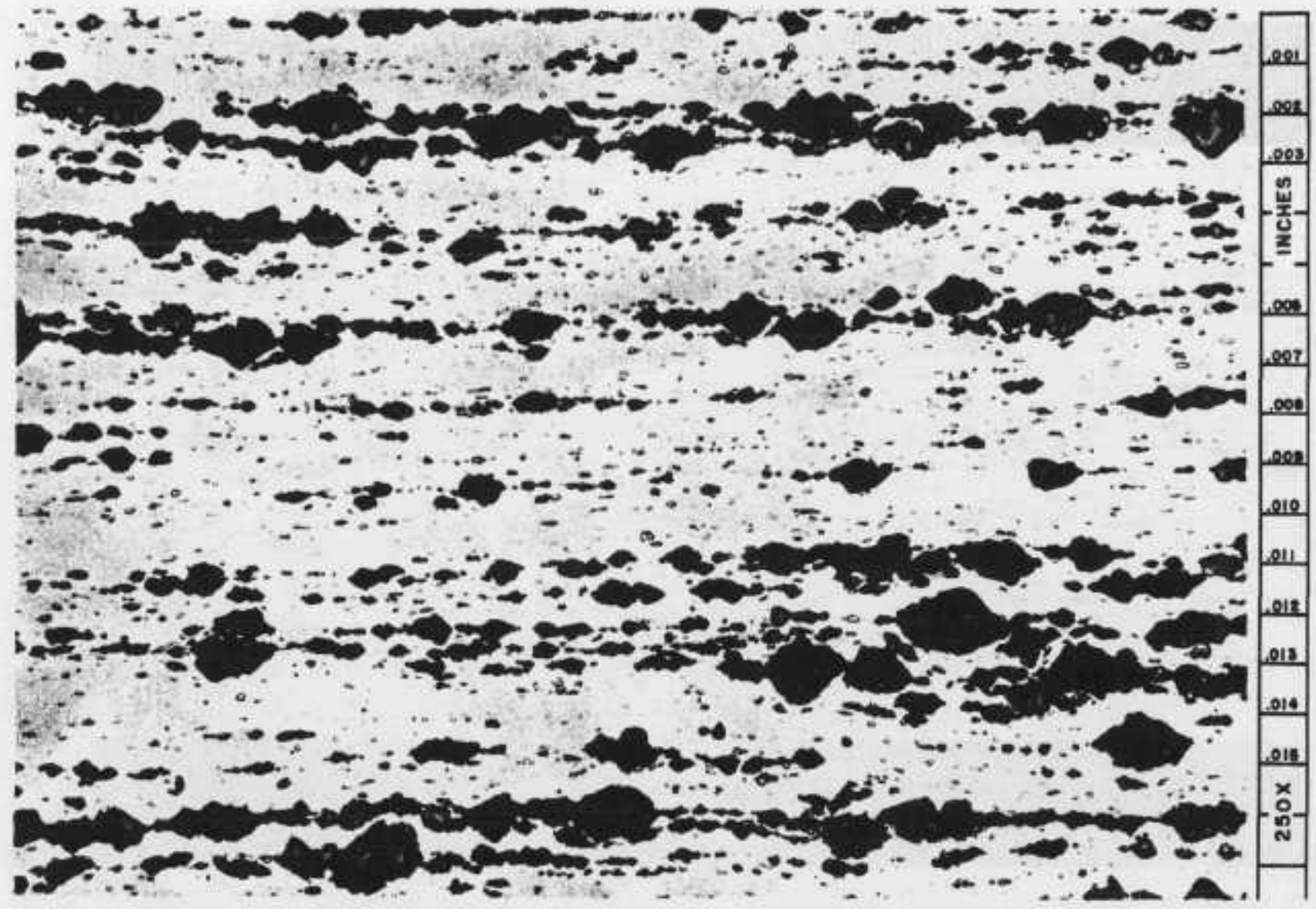

Fig. I - (Y18927) Typical Stringering and Fragmentation of $\mathrm{UO}_{2}$ in Stainless Steel Matrix of Cold-Rolled Fuel Plate. (From ORNL-CF-58-7-72) 


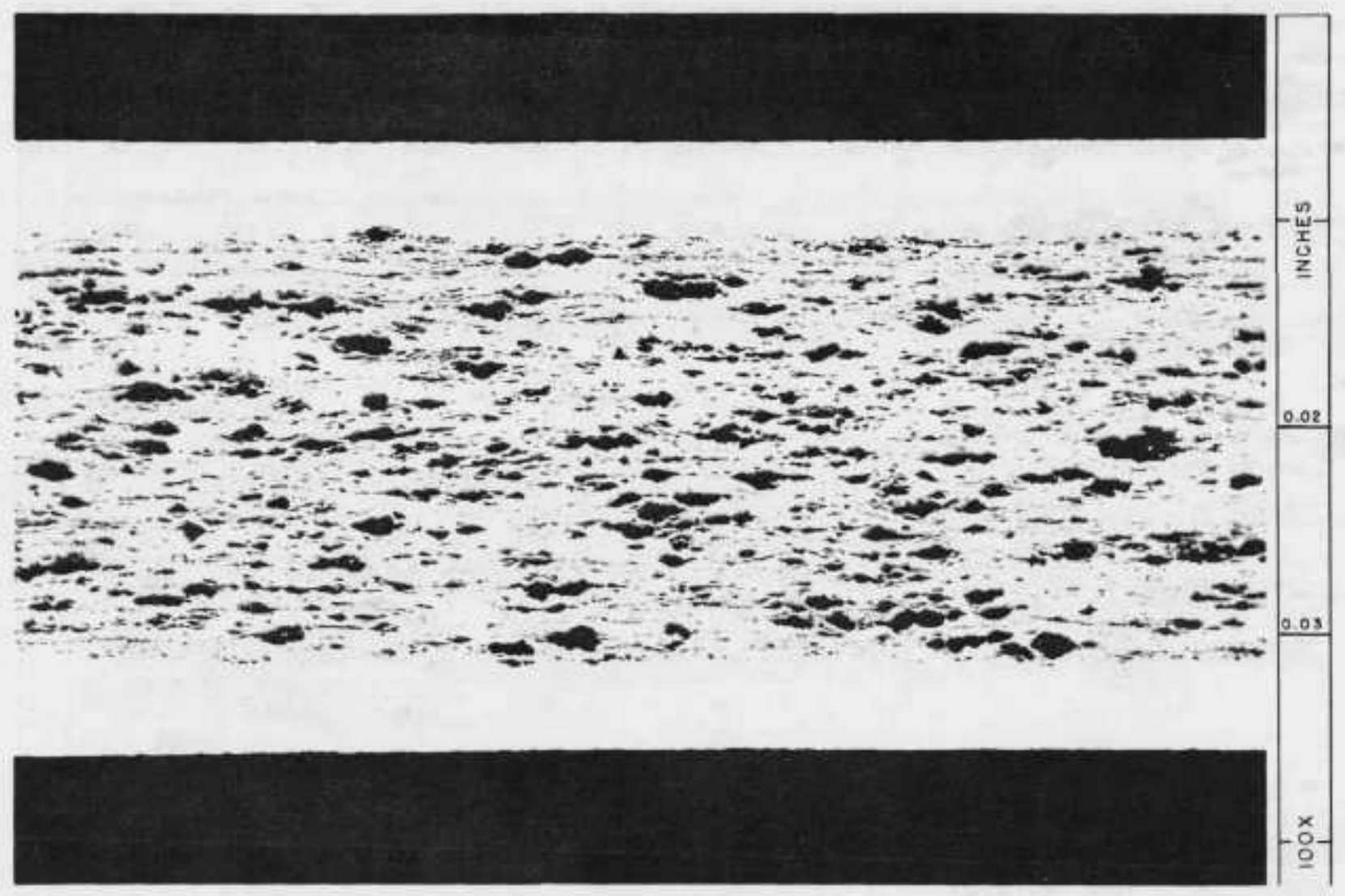

Fig. 2 Cross Section of $\mathrm{Eu}_{2} \mathrm{O}_{3}$ - Stainless Steel Flux Suppressor From ORNL-2726 
from each of the two fuel plates on a diagonal between core corners and approximately equally spaced, beginning two inches (2 in.) from the core-end interface and one-quarter inch (1/4 in.) from the core edge interface. These samples shall be dissolved In their entirety and chemically analyzed for total uranium and boron contents. The results shall be expressed in weight per cent of the specimens.

For each of the two plates the urantum requirement is:

1. The uranium content of each sample expressed in weight per cent shall be within plus or minus two per cent $( \pm 2 \%)$ of the tested plate average.

The boron requirement is:

1. The boron content of each sample expressed in weight per cent shall be within plus or minus twenty per cent $(+20 \%)$ of the tested plate average.

e. Bond Integrity

Five transverse samples equally spaced along the plate length and three longitudinal samples from each end equally spaced across the width shall be removed from two of the sample fuel plates. After proper preparation and etching, the samples, shall show no evidence of lack of bond at the following interfaces, clad to core, clad to frame, suppressor core to fuel core, suppressor to frame, and suppressor to clad, upon metallographic examination at 100 diameters.

f. Clad-Core-Clad Thickness

The ten transverse samples used in " $e$ " shall be metallographically measured to determine clad-core-clad thickness. As measured by filar micrometer eyepiece, all of the thicknesses at all points in the samples shall show compliance with specified thicknesses.

B. Total Plate Loading

Eight sample fuel plates shall be completely dissolved and analyzed for total uranium, boron and europlum contents. The averages of results of duplicate analyses for each of the eight sample fuel plates shall be within the following deviations from specification:

\begin{tabular}{|c|c|c|}
\hline Uranium & \pm & $5 \%$ \\
\hline Boron & $\pm \quad 12$ & 果 \\
\hline Europium & \pm & $x^{3}$ \\
\hline
\end{tabular}


h. End Conditions

The twelve longitudinal samples used' in "e" shall be examined metallographically. These samples shall show no evidence of the presence of core material in the inactive portions as dimensionally spectified or of the presence of volds at the core-frame interface.

i. Fragmentation and Stringering

One longitudinal sample at least one-half inch long shall be taken from the active and suppressant core of each of four sample fuel plates. When examined metallographically, none of these samples shall exhibit fragmentation and stringering greater than that illustrated in Figures I and II respectively. The europium oxide shall exhibit no evidence of reaction with the matrix, clad or frame material at magnifications up to $1500 \mathrm{X}$.

j. Qualification of Component Brazing

Examination of the brazed joints of a full size fuel element consisting of composite plates containing depleted $\mathrm{UO}_{2}$ must demonstrate the ability of the manufacturer to braze fuel elements officlently. The test fuel element shall meet all applicable dimensional requirements for brazed fuel elements as specified on the appropriate Alco Products, Inc., drawings. After appropriate sectioning of the fuel element longitudinally, the following examination shall be made.

1. Visual Inspection for Braze Quality

The following fillets shall be inspected:

$\begin{array}{ll}\text { Top Fillets } & \text { Bottom Fillets } \\ \text { Plate No. 1 } & \text { Plate No. 4 } \\ \text { Plate No. 5 } & \text { Plate No. 8 } \\ \text { Plate No. 9 } & \text { Plate No. 12 } \\ \text { Plate No, 13 } & \text { Plate No. 16 }\end{array}$

The following requirements shall be met:

1. A total of two inches (2 in.) of void in the braze joints of a fuel plate will be allowed. $A$ roid is defined as any area in which the braze metal is not at least flush with the inner surface of the side plate. The presence of voids in excess of the above amount is cause for rejection. 
2. Braze runout on any fuel plate in excess of sixtythree thousandths of an inch (.063 in.) from the inner surface of the side plates is cause for rejection.

3. Braze metal splatter or pitting over the active core section is cause for rejection

4. Any pitting or wash of the fuel plate caused by reaction with the braze metal in excess of one thousandth of an inch (.001 in.) deep is cause for rejection.

2. Microscopic Examination of the Brazed Fillet

Twehty-four (24) joints shall be examined. Specimens shall be obtained from the fuel element sections containing plates No, 1 to No. 4; transverse cuts shatl be made at distances of 3 inches, 12 inches, and 20 inches from the end of the fuel element. The joints shall be examined to determine joint quality and the length of brazing alloy overlaying the fuel plate as measured outward from the inner edge of the side plate. Any overlay in excess of 0,063 inches is cause for rejection. Braze metal volds or cracks shall be cause for rejection.

k. Qualification of Europium Master Suppressor Compacts

Two sample master compacts prepared in accordance with ALCONPE Specification No. S-5 shall be sectioned into three (3) onequarter inch (1/4 in.) strips taken from the middle and each end of the compacts. The average europium content of the six samples, expressed in weight per cent (wt. $\%$ ), must be within plus or minus two-tenths of one weight per cent $( \pm 0.2 \mathrm{wt} . \%)$ of the required concentration.

5. Conformance of Fabrication Procedure

These specifications cover materials and processes required to produce completed elements. The procedural specifications are specific for manufacturing these components at ORNL and other facilities, and represent a detalled guide for fabricators. It is recognized that because of differences in equipment, fabricators may be required to modify some of the detailed procedures to arrive at the same result. Prior approval for any deviation from these specifications must be approved by the Contracting Agency or its authorized representative.

Delivery of an acceptable product, including materials, dimensions, loading, and all other requirements, remains the responsibility of the manufacturer. 
The exact procedure used in fabricating the sample fuel plates which is proposed to be used in fabricating the active fuel plates shall be furnished to the Contracting Agency or its authorized representative at the conclusion of fabrication of qualification plates and at least one week in advance of the request for approval of qualification. Unless otherwise specifically authorized in writing by the Contracting Agency or its authorized representative, the procedure used in fabricating the sample fuel plates shall be strictly adhered to in fabricating the fuel plates and the fuel elements.

\section{Liaison and Inspgetion}

Free entry shall be given to the Contracting Agency or its authorized representative to all appropriate areas of the manufacturer's plant at any time during the term of the contract for fabricating the fuel elements. The manufacturer shall provide all reasonable assistance, factlities, and cooperation to the Contracting Agency or its authorized representative for determination of compliance with specification or procedure requirements or for inspection purposes as may be required.

The Contracting Agency or its authorized representative will maintain liaison with the manufacturer for the duration of the contract for the following purposes: (1) to provide necessary and reasonable technical assistance as may be required, (2) to inspect for compliance with the specifications and the approved fabrication procedure. The Contracting Agency or its authorized representative shall have the right at any time during the term of the contract to reject any and all pieces, parts, components, and products which do not meet the requirements of the specifications, or which have not been fabricated in accordance with the approved procedure, or which fail in any way to meet any of the requirements set forth in this document. Such inspection shall not relieve the manufacturer of any responsibtlity in any phase of fuel element fabrication or furnishing thereof.

7. Certification

Certification shall be furnished to the Contracting Agency, or its authorized representative that all materials used in the fabrication and furnishing of the fuel elements are in accordance with the requirements of these specifications. 


\section{CORE LOADING* SPECIFICATIONS AND A LIST OF DRAWINGS}

Loading Specifications for Control Rod Fuel Element

(Containing Internal Flux Suppressors)

Fuel Elements per Core

Fuel Plates per Fuel Element

U-235 per Fuel Element (grams)

422. 72

Total U-235 in Control Rod Fuel Elements (Kg)

B-10 per Fuel Element (Brams)

$2.11 \pm 0.5 \%$

Total B-10 in Control Rod Fuel el .360

Total B-10 in Control Rod Fuel Elements (grams)

$$
1.8 \pm 12 \%
$$

U-235 per Fuel Plate (grams)

$26.42 \pm 0.5 \%$

B-10 per Fuel Plate (milligrams)

$22.50 \pm 12 \%$

Europlum per Suppressor (grams)

$1.00 \pm 5 \%$

Since the loadings are subject to revision, the manufacturer shall obtain verification from the Contracting Agency or its authorized representative that the loadings are firm.

List of Drawings (Alco Products, Inc. Drawings)

Fuel Element

Fuel Plates Short

Fuel Plates Long

FP-(Exploded view prior to hot rolling)

Side Plate

Comb

Handle

Pin
D9-13 - 1030

D9-13-2149

D9-13-2149-1

AES-344

D9-13-2155

D9-13-2155-1

A9-13-2078

A9-13-2077

Drawings are included in the appendix. Since the drawings are subject to revision, the manufacturer shall obtain verification from the Contracting Agency or its authorized representative that the drawings contain the latest revisions and are firm.

* The loadings are finished product requirements. Allowances for fabricating losses must be made by the manufacturer. $365 \quad 018$ 


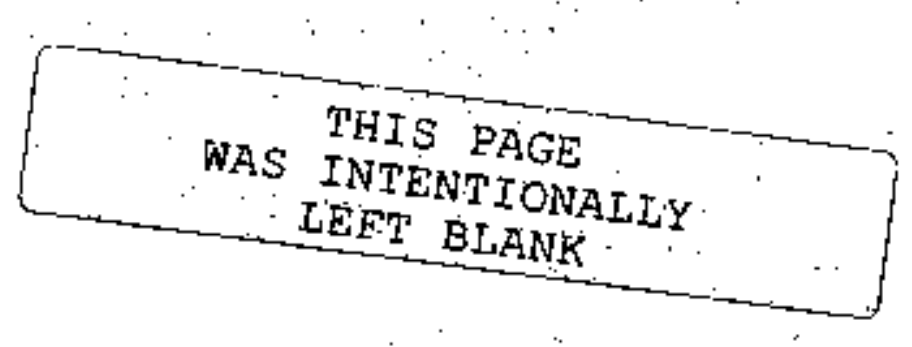


FLON DLAGRAM FÓA PUY-2A CONTROĹ ROD FUEL ELEMIENTS

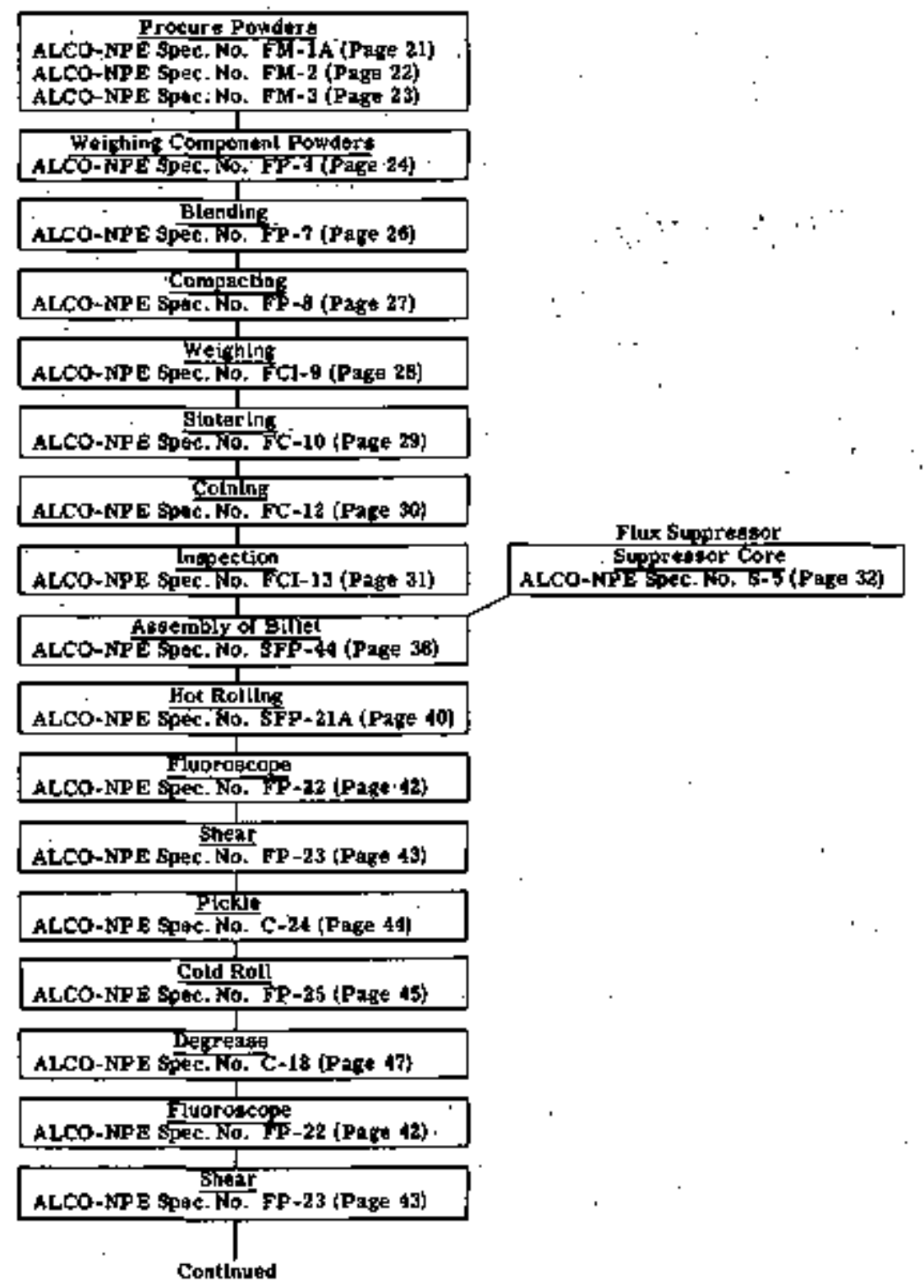




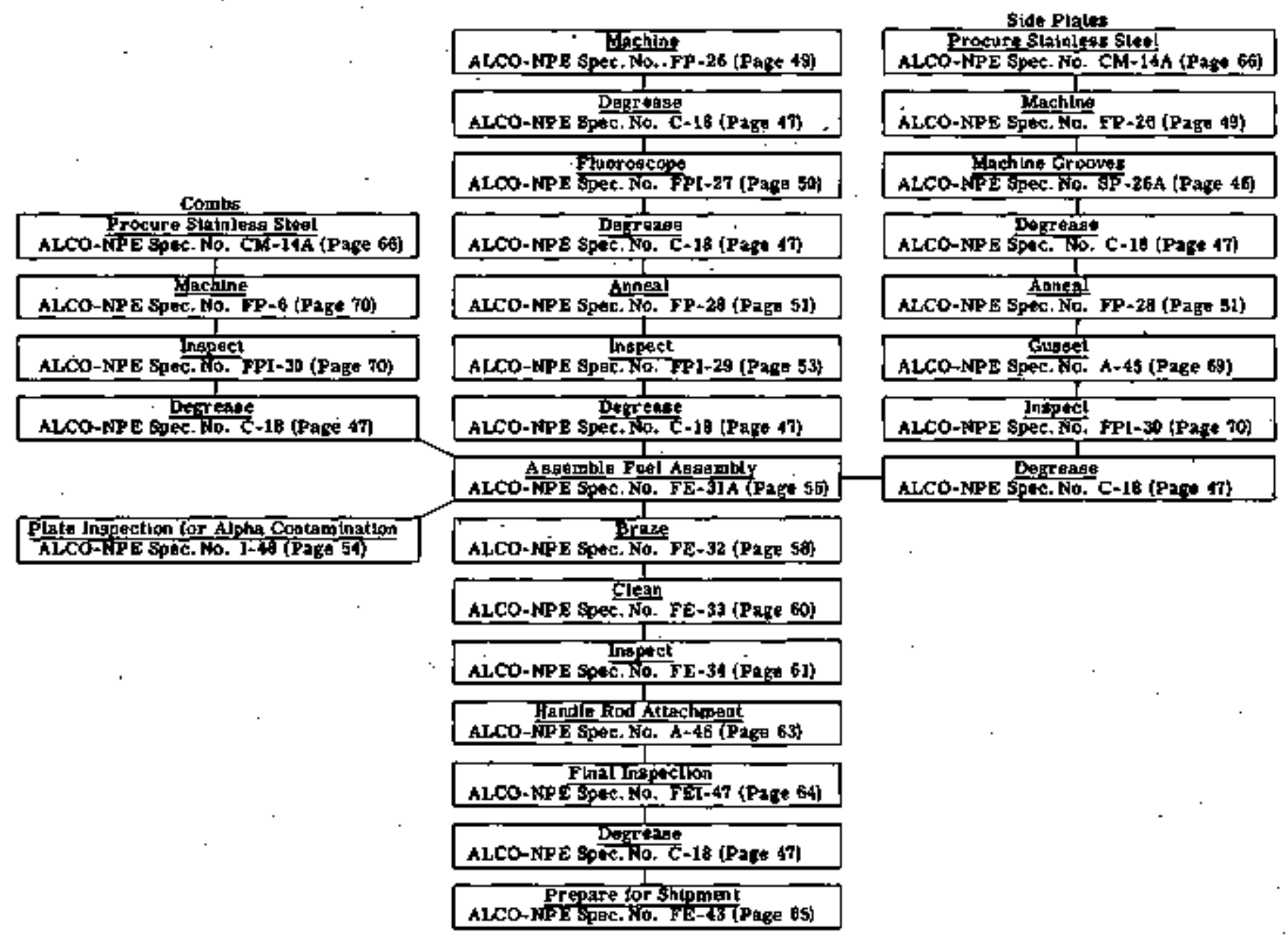

$3 \times 5 \cdot 20$ 
PROCESS AND MATERIAL SPECIFICATIONS

บธ 521 
Material:

Purpose:

Analysts:

Specification:
- Uranium Dioxide Powder ("Geneva" type)

- This specification covers $\mathrm{UO}_{2}$ powder for use in nuclear reactor fuel plates of the stainless steel clad dispersion type.

- UO with a total uranium content of approximately $88 \mathrm{wt} . \%$. U-235 isotopic enrichment $93 \pm 1$ wt. $\%$.

- This fuel shall be $\mathrm{UO}_{2}$ powder prepared by the "Geneva" process, as originally prepared in the $\mathrm{Y}-12$ Production Plant at Oak Ridge, Tennessee. The $\mathrm{UO}_{2}$ shall contain approximately $88 \mathrm{wt}$. \% total uranium and have a U-2\$5 isotopic concentration of 93 第 \pm 10. Particle size shall be $44-88 \mu$. The $\mathrm{UO}_{2}$ shall be free of agglomerates, platelets, rods, and clinging surface fines. 
ALCO-NPE Specification No, FM-2

Material: - Boron Carbide Powder

purpose: - This specification covers $\mathrm{B}_{4} \mathrm{C}$ for use as burnable polson in the core of stainless steel dispersion type fuel plates.

Analysis: $\quad-\quad \mathrm{B}_{4} \mathrm{C}$ containing approximately $76 \mathrm{wt}$. \% natural boron, B-10 isotopic concentration $18,5 \pm 1.5$ wt. 8 .

Particle Size: - Less than $44 \mu$.

Supplier: - As supplied by the following, or equivalent:

Norton Chemical Company

Worcester 6, Massachusetts 


\section{ALCO-NPE Specification No. FM-3}

Material:

Purpose:

Analysis:
- Stainless Steel Powder

- This specification covers staintess steel powder for use as matrix in dispersion type fuel efements for nuclear reactor cores.

- Type 304 LB stainless steel powder with .03 wt. 8 max. carbon content and approximately 2.5 wt. 8 silicon. The silicon is added primarily to prevent oxidation during preparation, however, it does result in particles with an irregular shape which leads to higher green strengths on cold pressing.

Particle Size: - 10 to $149_{\mu}$ of irregular shape

Suppliers: . - As supplied by the following, or equivalent:

Vanadium Alloys Șteel Company

Latrobe, Pennsylvania 


\section{ALCO-NPE Specification No. FP-4}

Title: $\quad$ - Weighing of Component Powders

Purpose: $\quad-\quad$ This specification covers the weighing of the following component powders for use in nuclear reactor cores:

Boron Carbide

Stainless Steel

Uranium Dioxide

Process: - - The component powders for each individual core are separately weighed and combined in a single blending jar. With the exception of posstble losses during subsequent pressing and sintering operation, this method offers accurate accounting of the critical ingredients, U-235 and B-10, in each fuel core within the limits of the accuracy of the weighing balance. Boron carbide is the first material loaded into the blending jar and is followed by the stainless steel, and finally the uranium dfoxide. This sequence permits the boron carbide and stainless steel powders to be handled in the conventional manner, thus eliminating the inconvenience of weighing these materials within a dry box, as is required during handling of finely divided UO2.

\section{a. Weighing of the Boron Carbide}

The burnable poison in the form of $\mathrm{B}_{4} \mathrm{C}$ is weighed to an accuracy of at least three-tenths of one per cent $(0.3 \%)$. A sheet of glazed paper with glazed side up and of known weight is placed on the pan. The $B_{4} C$ is added to the paper and accurately weighed. The material is then poured into a clean, wide-mouth, glass jar of four ounce ( 4 oz.) capacity. A camel's hair brush is used to brush any remaining particles of $\mathrm{B}_{4} \mathrm{C}$ into the jar, which is then capped.

b. Weighing of the Stainless Steel Powder

The stainless steel powder is weighed in exactly the same manner as the $\mathrm{B}_{4} \mathrm{C}$. The powder is weighed to a tolerance of one hundredth of one per cent $(0.01 \%)$. It is then transferred to a blending jar containing the prerecapped. 


\section{c. Weighing of $\mathrm{UO}_{2}$}

Weighing of the fissile compound is performed within a glove box in which the atwosphere is under a slight negative pressure. The box is equipped with a balance. A weighing accuracy of three one-hundredths of one per cent $(0.03 \%)$ is required. After weighing, $\mathrm{UO}_{2}$ is added to the jar containing the boron carbide and stainless steel powders. After removal from the glove box, the joint between the cap and jar is sealed with masking tape. The $\mathrm{UO}_{2}$ lot number is then marked on each jar.

Equipment: - Gram-atic balance, or equivalent. 
Title:

Purpose:

Process:

Equipment: - Cone blender or ball mill.

Results of NonCompliance:

6.59 


\section{ALCO-NPE Specification No. FP-8}

Title: $\quad$ - Compacting Fuel Powders

Purpose: $\quad-\quad$ This specification covers the compacting of fuel powders into a "green" compact. This is the initial operation in producing a compact for use in a fuel plate assembly. The "green" compact will be approximately ten per cent $(10 \%)$ greater in thickness than the finish dimension required for fuel plate billët assembly.

Process: - The contents of one container of blended fuel powder (ALCO-NPE Specification No. FP-7) are poured in a floating sleeve die, the jar brushed thoroughly, the powder levelled, and pressed at a minimum of thirtythree (33) tons per square inch for fifteen (15) seconds. Identity of compacts, by batches, is maintained. Batch size is determined by criticality limitations.

Lubrication: - A minimal amount of $10 \mathrm{wt}$. per cent C.P. Stearic acid 90 wt. per cent carbon tetrachloride lubricant is applied to the top of the die cavity and punch faces, as required. Stripes of lubricant may be applied fith a $1 / 4$ inch camel's hair brush around the top and bottom of the die cavity and to the punch faces. Excessive lubrication of punch faces should be avoided since $\mathrm{UO}_{2}$ can adhere to lubricants when the blend is poured into the die and slight segregation may occur if streaks or nonuniform coverage of die faces exists.

Cleanliness: - Analytical chemistry laboratory standards and procedures must be adhered to at all times.

Equipment: $\quad-\quad$ Powder Compacting Press

Glove equipped dry box encloses the die providing work area for powder transfer from container to die and storage of compacts in process. The glove box is maintained at a slight negative pressure and exhausted through an absolute filter to avold contaminating the surrounding area. 
Title:

Purpose:

Proceds:

Equipment:
- Weighing of Fuel Compacts after Cold Ptiessing

- This specification covers the weighing of "green" compacts (ALCO-NPE Specification No, FP-8) to determine that handling losses do not exceed allowable tolerance.

- The compacts are individually weighed. A weight loss in excess of two hundred fifty milligrams (250 $\mathrm{mg}$.) from the charged weight is the basis for rejection.

- Balance of more than 150 gram capacity and accuracy of ten milligrams.

Glovebox. 
Title: $\quad-\quad$ Sintering of Compacts

Purpose:

Process: $\quad-\quad$ The hydrogen atmosphere used in heating and cooling must be maintained at a dewpoint of minus sixty degrees Fahrenheit $\left(-60^{\circ} \mathrm{F}\right)$ or better, as measured at the gas inlet of a lepaktight furnace. The "green" compacts are loaded on a stainless steel screen. (No. 12 mesh, type 316) in a stainless steel sintering boat (type 316) designed to permit uniform heating. If stacked two high, they are separated by stainless steel screens. The compacts are charged into the furjace cold chamber and hold until the hydrogen dewpoint retutis to minus thirty degrees Fahrenheit $\left(-30^{\circ} \mathrm{F}\right)$, then they are moved into the hot zone of the furnace. Sintering time is one hour and fifteen minutes (1-1/4 hr.) at two thousand one hundred fifty degrees Fahrenheit $\left(2150^{\circ} \mathrm{F}\right)$, plus or minus twenty-five degrees ( $2^{\circ} \mathrm{F}$ ). After sintering, they are moved to the cooling chamber and cooled to four hundred fifty degrees Fahren-. heit $\left(450^{\circ} \mathrm{F}\right)$. From this temperature they may be air cooled to room temperature. The identity of the compacts is maintained and recorded.

Equipment: - Hydrogen atmosphere furnace capable of maintaining the above temperatures, with cooling chamber.

Source of hydrogen of the low dewpoint required,

Accurate dewpoint measuring instrument.

$$
5.5 \quad 30
$$




\section{ALCO-NPE Specification No. FC-12}

Title: $\quad-\quad$ Coining of Fuel Compacts

Purpose: $\quad-\quad$ This specification covers the coining of sintered fuel compacts (ALCO-NPE Specification No. FC-10) of fuel dispersion for use in fuel plates.

Process: $\quad-\quad$ The sintered compact is carefully inserted into the dry-box enclosed die previously used for compacting (ALCO-NPE Specification No. FP-8) and pressed at thirty-three tons per square inch (33 TSI) for fifteen seconds (15 sec.).

Equipment: $\quad-\quad$ Equipment used in ALCO-NPE Specification No. FP-8 is used for this operation.

$4.2 \quad 31$ 
ALCO-NPE Specification No. FCI-13

Title: $\quad-\quad$ Final Inspection and Storage of Fuel Compacts

Purpose: $\quad-\quad$ This specification covers the final inspection of fuel compacts (ALCO-NPE Specification No. FC-12) of fuel dispersion for use in fuel plates.

Process: - The finished compacts are visually and dimensionally inspected. Obvious flaws or surface imperfections due to nicks, cracks, spalling or breaking are cause for rejection. The finished compacts are wrapped in paper in batches and stored in a dessicator. If the storage period is more than 48 hours, a vacuum dessicator will be used.

Equipment: - Micrometers

Low Power Magnifier

Dessicator and vacuum dessicator

3.332

31 
Title: $\quad$ - Eurppium Bearing Flux Suppressor Core

Purpose: $\quad-\quad$ This specification covers the materials and process for preparing the europium flux suppressor core. The flux suppressor, a small europium-bearing segment, forms a part of the fuel plate core at one end of the composite fuel plate. The integral suppressor serves the function, of minimizing flux peaking due to a Wilkins' effect in the axial void junction at the fuel-absorber interface in the control rod.

Process: $\quad$ - The flux suppressant, europium oxide, is dispersed in a matrix of elemental powders. The iron, nickel and chromium elemental powders $(-325 \mathrm{mesh})$ are mixed to provide a matrix of the following composition:

Hydrogen Annealed Electrolytic Iron (99.0\% $\mathrm{Min}_{\text {。 }}$ )

Electrolytic Chromium

- 71 wt. $\%$

Carboniyl Process

Nickel $\left(99.5 \% \mathrm{Min}_{\mathrm{o}}\right) \quad-11 \mathrm{wt}_{\mathrm{o}} \%$

The silicon content of each of the elemental powders is restricted to a maximum of $0.03 \mathrm{wt}$.

Maximum of other impurities:

$\begin{array}{lll}\text { Oxygen } & - & 0.100 \text { wt. } \% \\ \text { Carbon } & - & 0.02 \text { wt. } \% \\ \text { Cobalt } & - & 0.02 \text { wt. } \% \\ \text { Cadmium } & - & 0.002 \text { wt. } \% \\ \text { Bpron } & - & 0.002 \text { wt. } \% \\ \text { Rare Earths } & - & 0.002 \text { wt. } \%\end{array}$

Flux Suppressor Core Preparation

1. Preparation of europium oxide - The europium oxtde obtained from the various vendors is normally of low density and extremely fine particle sizes. Such material is not readily suitable as a powder metallurgical dispersoid. Prior to incorporating the oxide 
in a stainless steel matrix, the material is conditioned by a high-firing process. The various stages of this operation are as follows: (1) inspection of the as-received oxide, (2) pressing, (3) firing, and (4) crushing.

(1) Inspection of as-received europium oxide, - It is recommended for optimum conditioning properties that the as-received oxide be obtained "dead-burned" from the oxalate form with no additional intermediate temperature treatments. . Each batch of received oxide is chemically analyzed for total europium oxide . The materlal should contain a minimum of $98 \%$ europium oxide. The thoria content is determined by alpha counts in excess of background is considered contaminated and rejected.

(2) Pressing - Prior to high firing, the received powder is pressed into small cylindrical pellets to facilitate subsequent handling. Approximately $35 \mathrm{~g}$ of the material, measured in a $10 \mathrm{cc}$ stainless steel beaker, is poured into the cavity of a double-acting 0.8 in. diameter die, leveled, and pressed into pellet form at a pressure of about 4 ton/ $/ \mathrm{n}^{2}$. The resulting $0.8 \mathrm{in}$. diameter $\times 0.8 \mathrm{in}$. long pellets are sufficiently strong to handle without spallation.

(3) Firing - Approximately 10 pellets weighing between $300-350 \mathrm{~g}$ comprise the firing batch size. The individual pellets are placed in a tungsten crucible approximately $2 \times 2 \times 7$ in, in size which is constructed by edge welding $1 / 8$ in. sheet stock. The loaded tungsten crucible is inserted in a reactor grade graphite crucible mounted in the center of an induction coil. Amorphous thermatomic carbon is packed between the graphite crucible and outer quartz furnace to serve as an insulator. A reactor grade graphite block with attached off-gassing stems is placed over the graphite crucible to prevent the thermatomic graphite from contaminating the europium oxide pellets. The remainder of the quartz tube is then filled with thermatomic 
carbon and finally capped with a gas-tight, brass end plug. A hydrogen gas stem is attached to the lid to permit passage of hydrogen (-60 $0^{\circ} \mathrm{F}$ dewpoint) to the pellets during the firing and cooling of operation. The exit hydrogen gas escapes through the stem attached to the top of the graphite crucible. The pelfet firing is carried out at $3090^{\circ} \mathrm{F} \pm 25$ for a period of three? hours. The power is varied to control the rate of temperature rise in the furnace; a rate of $570^{\circ} \mathrm{F} / \mathrm{hr}$ is the average rate. Temperature measurements are made on the surface of the pellets by sighting an optical pyrometer through the off-gassing stem. Upon completion of the firing, the power is shut off and the furnace air cooled to approximately $300^{\circ} \mathrm{F}$ at which time it is disassembled and the fired pellets removed.

(4) Crushing - The fired pellets are crushed to $\mathbf{- 3 2 5}$ mesh size in a mortar and pestle uging a series of inter mediate screening operations. Initially, onethird of the fired batch size is placed in a mortar and crushed using only impact-type strokes. Circular grinding motions have been found to produce considerable fines in the crushed oxide. After the initial comminution, the product is placed on a series of vibrating screens which separate out the $:+100,-100_{1}^{*}-270$, tid sor and -325 mesh fractions. Each fraction is then recrushed until the entire matertal is of a $\mathbf{- 3 2 5}$ mesh fraction. The various sizing separations are necessary to mintmize fines during this operation. The final product from each batch is examined macroscoptcally for the particle shape and size. Since the percentage of europium generally increases during high-firing, a representative sample of each batch of high-fired oxide is analyzed by wet chemistry for total europium. A specimen from each processed lot or batch of europium oxide shall be tested for weight change by firing in a dry hydrogen (dewpoint at least $-60^{\circ} \mathrm{F}$ ) atmosphere for $1-1 / 2$ hours at $2250+25^{\circ} \mathrm{F}$. For fir ing, the specimen shall be placed on a molybdenum lined Type 316 stainless steel boat heated in an inconel tube furnace. The specimen shall be cold pressed in a $1 / 4$ inch diameter die at a pressure of $3100 \mathrm{psi}$ before firing. 
ALCO-NPE Specification No. S-5 (Cont.)

Any weight gain, or loss, in excess of 0.008 grams will be cause for rejection of the lot or batch of europium oxide which is represented by the specimen. A 1. 500 gram test specimen shall be used. After high firing the europium oxide must be shipped, stored, and handled under conditions which preclude the pickup of any moisture.

2. Manufacture of the Dispersion of Europium Oxide in Stainless Steel

The inserted flux-suppressor portion of the core is a section obtained from the sintered and coined compact containing approximately 28 wt. $\%$ europium oxide homogeneously dispersed in austenitic stainless steel.

(a) Calculations - The flux suppressor and matrix powders are specifted in terms of europium and stainless steel. Since the europium is in the form of europlum oxide, it is necessary to determine by calculation the quantities of these materials whtch are to be incorporated in each core. Each batch of europium oxide which is treated is analyzed for europium. After high-firing the compound shall contain a minimum of 85 wt. 0 europium. The stainless steel matrix is obtained by sintering of the elemental iron, nickel and chromium powders.

Sample calculations illustrating the determination of the quantities of material required for one flux suppressor are attached in the appendix.

The following illustrates the techniques used for obtaining one master compact composed of the listed quantities of materials:

$\begin{array}{llr}\text { Europium oxide } & - & 8.11 \mathrm{~g} . \\ \text { Fe powder } & - & 14.9 \mathrm{~g} . \\ \text { Ni powder } & - & 2.3 \mathrm{~g} . \\ \text { Cr powder } & - & 3.6 \mathrm{~g} .\end{array}$


(b) Weighing of component powders - The europium oxide, nickel, iron and chromium powders are separately weighed in quantities to provide material for one core, $2.180 \times 1.8 \times 0.068 \mathrm{in}$. in size. The 2. 180 in. dimension was selected for convenient fit into the frame with no subsequent machining; the 1.8 in. dimension was arbitrary; and the 0.068 in. thickness was established experimentally. The powders are weighed on an analytical balance to within an accuracy of $\pm 0.3 \%$.

(c) Blending - The powders are blended in order to obtain a homogeneous mixture of the europium oxide and matrix material. A modified U. S. Stoneware Company Double Cone Blender, Model 733, is used. The blender cones are replaced by a pair of two-quart steel cans mounted on the motor shaft at an angle of 30 degrees with the vertical. Five jars, each containing the specified quantities of europium oxide, iron, nickel and chromium are loaded into each can with sufficient padding to prevent breakage of the jars during the blending operation. The cans are rotated at this oblique angle for three hours, after which the jars are removed and uncapped.

(d) The blended powders are cold pressed into a compact using the floating sleeve powder-metallurgy die used in ALCO-NPE specification No. FP-8. Since no contaminated material is present, this operation is done in a conventional manner. After the powder is carefully leveled in the die cavity, a pressure of 10 tsi is applied to the system for a period of 15 seconds. Care must be exercised in removing the thin, fragile green wafers to prevent corner breakage. To avoid unnecessary handling the pressed compacts are removed from the die and placed directly on the sintering boat.

(e) Sintering of "green" compacts - The equipment and procedure utilized is similar to that described in ALCONPE- Specification No. FC-10 for the fuel compacts with the exception that the sintering temperature is 
ALCO-NPE Specification No. S-8(Cont.)

$2250^{\circ} \mathrm{F}$ for 1 hour and a molybedenum-lined boat is provided instead of the conventional stainless steel boat to. prevent possible reaction of the europitim oxide.

(t) Repressing of sintered compacts - After careful loading into the original die, the sintered compacts are pressed under a pressure of 33 tsi for 15 seconds to improve densification.

(g) Resintering of compressed compacts - This operation is identical as that described in (e) above.

(h) Coining of sintered compacts - After careful loading into the original dies, the sintered compacts are coined at 33 tisi for 15 seconds. The resultant density is approximately $80 \%$ of theoretical.

(i) Inspection - The compacts are inspected and if chips and flaws are observed, that portion of the compact is rejected. The compact is also rejected if the thickness measurement of 0.068 in. varies more than $\pm 0.003 \mathrm{in}$.

(j) Shearing - The sintered and coined compact is sheared along the 1.8 in. dimension to produce sections which are 2.180 in. long $x 9 / 32$ in. wide. The width dimension is sheared $w$ thin $1 / 16 \mathrm{in}$. of nominal.

(k) Machining - The section width is ground dry to 0.274 in. $x 0.001$ in. yielding a section 0.068 in. $x$ 0.274 in. $x 2.180$ in.

(1) Weighing - The europium oxide stainless steel flux suppressor must be within $5 \%$ of the designed requirement in section 2-b. 
ALCO-NPE Specification No. SFP-44

Title:

Purpose:

Process:
- Control Rod Fuel Plate Billet Assembly

- This specification covers the stainless steel components used to enclose the fuel and suppressor compacts, their preparation, the method of assembly, identification, and welding of the billet assembly. The billet is subsequently hot roll-bonded.

\section{- 1. Material Preparation}

Each fuel plate billet requires two cover plates and one picture frame in addition to fuel and flux suppressor compacts. Cover plates are fabricáted from 0.078 in. \pm 0.005 in. stainless steel sheet which is cold rolled to a thickness of $0.067 \mathrm{in}_{\mathrm{o}} \pm 0.001 \mathrm{in}$. in size. Recommended practice for economical use of material is to reduce $9-\mathrm{in}$. $\times 36$ in. strips of 0.078 in. thickness before final shearing.

Picture frames are fabricated from $5 / 16$ in. stainless steel plate whtch is cold rolled to 0.276 in. \pm 0.002 in. Picture frames are also sheared to 4-7/16 in. $x 4$ in. $\pm 1 / 16$ in. in size. Recommended practice is to cross roll $18 \mathrm{in}$. squares of the $5 / 16$ in. plate to $0.276 \mathrm{in}$. thickness before final shearing. A hole, 1.910 in. $\times 2.210$ in. with $1 / 8$ in. corner radius, is then punched from the center of the picture frame to accept both fuel and flux suppressor cores. At one end of the 1.910 dimension, the inside corners are machined square to allow a snug fit of the suppressor section between the fuel core and the frame.

2. Assembly and Welding of Billets

A small 1/4 In. diameter stainless steel rod is welded at the center of the square cornered end of the frame which will be trailing during hot rolling. Immediately prior to billet assembly, the stainless steel is degreased and both surfaces of the picture frame and are thoroughly cleaned by scratch brushing the surfaces of the cover plates that will contact the picture frame with a power-driven stainless steel brush. The 
fuel core is inserted into the picture frame cavity followed by the flux suppressor core which fits snugly between the end of the fuel core and the end of the frame which has the attached identification marker. The cover plates are placed on top and bottom to form a sandwich and are immediately resistance spot-welded to the picture frame. Four $1 / 4$ in. diameter welds are placed $1 / 2$ in. in from the edge of the billet at the center of each side. A 25-KVA Resistance Welder Corporation Model T-52951 spot-welding machine is used. The cover plates are also welded to the picture frame plate by the tungsten inert-gas method. Since the object of the welding is to prevent possible shifting of the billet components during initial hot rolling operations, only a seal weld is required. The four corners are left unwelded for a nominal distance of $1 / 4$ inch to permit escape of entrapped gases during the initial passes through the hot-rolling will.

A vacuum dessicator is used for storage if the billets are not hot rolled immediately after assembly.

Equipment: $\quad$ - 25 KVA Resistance Welder 
ALCO-NPE Specification No. SFP-21-A

Title:

Purpose:

Process:
- Hot Rolling of Control Rad Fuel Plates

- This specification covers the hot rolling of the assembled and welded components (ALCO-NPE Specification No. SFP-44) to obtain the clad and frame to core bond, and dimensionally prepare the resultant composite fuel plate for subsequent processing.

- The billet is hot rolled to ten one thousandths of an inch plus or minus two thousandths $(0.010+.002$ inches) above the final thickness of the finished cold rolled fuel plate. The first two (2) passes, each at ten per cent (10\%) reduction, will serve to seat the components. Subsequent reductions may be increased to a maximum of forty per cent $(40 \%)$ per pass.

In each rolling pass the billets are gripped at the end marked by the projection so that the opposite end is always the first end to enter the rolls.

Caution: Special care is exercised to insure the direction of rolling remains the same by identifying the europium bearing tail of the billet (ALCO-NPE Specification No. SFP-44).

The billet is turned over, top to bottom, between each pass. A minimum of four (4) inches of inactive material is required beyond the ends of the fuel plate. The excess may be trimmed during hot rolling, as required, to fit the furnace length and to facilitate handling. The tralling end should be identified by a scribe mark on the inactive end. The disperston type core can be delineated from the inactive end material by a difference in heat color.

Heating is done in a leaktight muffle furnace using a hydrogen atmosphere with a dewpoint of minus sixty degrees Fahrenheit $\left(-60^{\circ} \mathrm{F}\right)$ at the furnace inlet. The flow must be adequate to prevent oxidation in the furnace. The furnace must be capable of maintaining a temperature of twentyone hundred degrees Fahrenheit plus or minus twenty-five degrees $\left(2100 \pm 25^{\circ} \mathrm{F}\right)$ over a muffle length of thirty-two inches (32 inches). The billets are heated in a furnace at 
twenty-one hundred degrees Fahrenheit $\left(2100^{\circ} \mathrm{F}\right)$ for at least twenty minutes (20 min.) prior to the first pass and reheated for at least two minutes ( 2 min. ) between subsequent passes. The thickness is checked with a micrometer near the end of the fabrication schedule. After the final pass, the rolled blllet is replaced in the muffle for a five minute $(5 \mathrm{~min}$.) anneal, and then is air cqoled.

The fuel and suppressor compact identitles must be retained throughout the processing. After the fuel plates are cooled, the identification is metal stamped on the inactive section at the end opposite the flux suppressor near the edge of the plate and recorded.

Rolls, tables, and furnace hearth or muffle must be kept clean of oxides or other forelgn material that may adhere to the work surfaces. If foreign material is trapped between the billet and the rolls, it is forced into the billet and the cladding continuity may be broken or its thickne'ss altered. Surface imperfections in excess of one thousandth of an inch (0.001 in:) in the finished fuel plates are cause for rejection. Therefore, extreme care must be exercised during the hot rolling operation. Roll parallelism must be maintained and the billets fed perpendicularly to the rolls to avoid rainbowing of the rolled billets.

Equipment: - Hydrogen atmosphere furnace capable of malntaining required temperatures.

Source of hydrogen of the dewpoint required.

Dewpoint measuring instrument. Alnor dewpolnter or equivalent

Rolling mill of a capacity to produce straight plates of uniform thickness. 
ALCO-NPE Specification No. FP-22

Title:

Purpose:

Process:
$48 \quad 43$

Equipment: - 175 KVP X -ray machine with fluoroscope screen.
- Composite Plate Core Layout

- The hot rolled plates are fluoroscoped to delineate the core section for determination of shearing and/or machining boundaries to remove the excess inactive material from the edges and ends.

- While being fluoroscoped, a slotted picture frame type template is center ed over the core and used to mark scribe lines for shearing and/or machining. The template contains slots at the dimensions to be marked on the plate and the slot edges are used in scribing the cutting lines.

Shearing Layout - The shearing template shall allow excess material required for subsequent operations, i. e., cold rolling and machining. The accuracy of the scribed lines that are used for the shearing operation prior to the final machining is such that the sheared edge may be used for locating the plates in the final machining fixture.

After hot rolling, the suggested template locates scribe lines $1 / 2$ inch beyond the sides of the fuel core and 3 inches beyond the ends, for both long and short plates.

After cold rolling, the suggested template locates scribe lines allowing a sheared plate width approximately.085 in. wider than the final machined plate. The lengths are sheared to provide approximately $1 / 64$ inch excess inactive material to be removed in final machining.

Identification - The identification prior to the cold rolling operation is heavily metal stamped just inside the scribed lines at the same end of the plate that had been previously identified. The Identification prior to the final machining operation is inscribed with a Burgess Vibro tool in numbers about three-eighths inch ( $3 / 8$ in. ) high and far enough from the centerline to prevent obstruction by combs that may be used at the plate ends in the fuel element.

Caution: Special care is exercised in identification to insure identifying the europium bearing end of the fuel plates. 
Title:

Purpose:

Process:

- Shearing

- This specification covers the shearing of material or components used in the manufacture of fuel elements.

- Guides, jigs, fixtures, and hold-downs conducive to facllitating the operation are permitted. Extreme care must be exercised when handling clad materials so that the cladding is not damaged. Cladding material thick-. ness is of the order of flve thousandths of one inch (0.005 in.). Therefore, all contacting surfaces must be smooth and free of protrusions or sharp edges which may inadvertently be the cause of cladding destruction, indentation, or weakening. Hold-down unit pressures must be such that the cladding is not destroyed or weakened. Good housekeeping must be practiced at all times to avoid cladding pickup of foreign items such as dirt. chips, slivers, etc.

Proper knife clearances must be utilized to avold tearing or slivering of the sheared edge.

Equipment: - Shear 
ALCO -NPE Specification No. C-24

Title: $\quad-$ Pickling

Purpose: - This specification covers the pickling of stainless steel fuel element components to remove oxides and other surface contaminants or adherents that may interfere with subsequent processing, or that are derimental to the final product. The following pickling solution is not to be used for plckling the composite plates after flatten annealing or brazing.

Process: $\quad-\quad$ The work is pickled in an aqueous solution of fifteen per cent nitric acid and five per cent hydrofluoric acid $\left(15 \% \mathrm{HNO}_{3}-5 \% \mathrm{HF}\right)$ at about one hundred thirty-five degrees Fahrenheit $\left(135^{\circ} \mathrm{F}\right)$ until the surface is clean. After pickling, the work is immediately and thoroughly washed with water to remove all traces of acid. The time required for pickling will increase as the acid is depleted. Periodic checks of the acid concentration shall be made.

Health Hazard: - This acid solution will attack the human body very rapidly; therefore, the pickling tanks should be well hooded and exhausted. Protective clothing, helmets, and gloves are a prerequisite to entering the pickling area. Water showers and eye sprays are to be provided for rapid removal of any acid that may be accidentally splashed on the personnel.

Safety: - Some acid concentrations react violently; therefore, the mixing sequence will be to put the measured proportion of water required in the pickling tank and then slowly add the required amounts of acids while stirring the bath.

Equipment: - Actd resistant tanks. Carbon block or plastic lined tanks are recommended. 
ALCO-NPE Specification No. FP-25

Title:

Purpose:

Process:
- Cold Rolling of Plates

- This specification covers the cold rolling of plates to final size.

- Care must be exercised to avoid excessive fragmentation and stringering of the dispersion particles in the composite plates, therefore the maximum permissible reduction per pass is one thousandth of an inch (0.001 in.). Small reductions permit the flow of matrix material so that the majority of the deformation occurs within the matrix, minimizing fragmentation of the dispersed particles. The composite plate thickness is measured over the section containing the dspersion. The length of the core is also important, and since length and thickness vary inversely percentagewise, the length tolerance generally becomes the limiting factor. The fuel plate shall be rotated about the transverse and longitudinal axes between passes. Roll parallelism and good work feeding are important requirements for producing straight plates.

Extreme care must be exercised when handling clad materials so that the cladding is not damaged. Cladding materfal thickness is five thousandths of an inch $10.005 \mathrm{in}$.). Therefore, all contacting surfaces must be smooth and free of protrusions or sharp edges which may inadvertently be the cause of cladding destruction or weakening. Good housekeeping must be practiced at all times to avoid cladding damage by forelgn items such as dirt, chips, slivers, etc. , being entrapped during rolling.

Equipment: $\quad-\quad$ Rolling Mill capable of producing straight plates of uniform thickness. 
ALCO-NPE Specification No. SP-26-A

Title:

Purpose:

Process:

Lubrication:

Equipment:
- Side Plate Grooving

- This specification covers the machining of grooves in the stainless plates (ALCO-NPE Specification No. FP-26) to be used as the side plates of the fuel element (ALCO-NPE Specification No. FE-31).

- Conventional machine shop practice for the machining of stainless steels may be used to groove the side plates per the appropriate drawing. Both gang milling and planing have been used. Special care is exercised to insure that the dimensions between the grooves and edges of the side plates are correct. Full plate length vacuum chucks have been used to hold the work during machining. Carbide tipped cutting tools are recommended.

- A heavy sulfur-base cutting oll; or equivalent may be used for lubrication.

- Milling machine or planer. Vacuum chuck. 
Title: $\quad-\quad$ Vapor Degreasing

Purpose: $\quad-\quad$ This specification covers the degreasing of parts to prepare the surfaces for subsequent processing or to clean the finished product prior to shipment and installation in the nuclear reactor.

Process: $\quad$ - Vapor degreasing shall be accomplished by the following methods:

a. All parts entering the degreaser shall be dry. Soft annealed material must be handled very carefully to avoid bending and distortion.

b. Load parts onto racks in the condensing zone of the degreaser so that they do not touch each other, and in such a manner as to insure complete drainage of solvents.

c. Lower or raise finished parts in the machine at a rate not to exceed twelve inches (i2 in.) per minute and immerse in vapor phase. Unfinished parts can be immersed at any rate. Spray with clean solvent during immersion time.

Keep the spray nozzle below the vapor line during spraying. Allow parts to remain in vapor until condensation ceases, three to five minutes ( 3 to $5 \mathrm{~min}_{\text {. }}$ ). Parts shall be completely dry before removing from the degreaser. After removal of finished fuel elements, clean dry air is carefully blown through the assembly to remove any solid debris. Finished fuel elements shall be degreased horizontally.

Bath Requirements:

- 1. Perchloroethylene - Operate between two hundred fifty and two hundred sixty degreas Fahrenheit $\left(250-260^{\circ} \mathrm{F}\right)$.

2. Trichloroethylene - Operate between one hundred elghty-five and one hundred ninety degrees Fahrenheit $\left(185-190^{\circ} \mathrm{F}\right)$.

NOTE: The above solvents shall contain a neutral inhlbitor to prevent acid formation due to hydrolysis. Other types of inhibitors are not permitted.

3. The solvent shall be checked at least weekly for boiling point. Solvent shall be completely replaced when the boiling 
ALCO-NPE Specification No. C-18 (Cont.)

point of perchloroethylene exceeds two hundred sixty degrees Fahrenheit $\left(260^{\circ} \mathrm{F}\right)$ or boiling point of trichloroethylene exceeds one hundred ninety-five degrees Fahrenhit $\left(195^{\circ} \mathrm{F}\right)$.

Safety: - The solvents are hazardous. Every precaution shall be taken to protect personnel from the solvents which have a toxic effect when inhaled.

Equipment: - Vapor Degrease

$\cos ^{2} \quad 48$ 
Title:

Purpose:

Process:

Lubricants: - Standard stainless steel cutting lubricants are acceptable.

Cutting Tools: - Carbide or carbide tipped cutting tools are recommended whenever practical for tool life and to minimize the possibility of smearing the cuts with cutting tool material that may have a high neutron cross section and/or long half-life.

Equipment: - Milling machine.

- Final Machining of Fuel Plates or Side Plates

- This specification covers the final machintng of fuel plates. The plates are machined to length and width prior to assembling into the fuel assembly grooved side plates to form a fuel assembly. The side plates are final' machined to length and width prior to groove milling.

- The plates may be stacked for straddle or duplex milling to width, and side milling to length. The stacked plates are sandwiched between one-eighth inch (1/8 in.) thick aluminum cushion plates that protect the plates from scratching and deformation when locked in the machining fixture. A bridge-type fixture bolted to the machine table is used to hold the plates during machining. Removable stops are used for positioning the plates during the bolting of the bridge. After wapor degreasing, the machined plate edges are lightly deburred by hand filing. Special care is taken to prevent rounding of the edges. Plates are final machined, including tapers and holes where required. 
ALCO-NPE Specification No. : FPI-27

Title: $\quad-\quad$ Machined Fuel Plate: Fluoroscopic and:Visual Inspection

Purpose: $\quad-$ - This specification covers the fluoroscoptc inspection of the fuel plates to determine their acceptability with respect to core width and length and edge and end cladding width.

Process: - - Suggested method of fluoroscopic inspection ts by means of a template centered over the core. The template contains slots over the critical areas of core width and length, marked to show maximums and/or minimums on a go-nogo basis. The acceptability of the plate is determined with respect to core width and length and edge and end cladding width.

Fuel plates that fatl this inspection normally are radiographed as a positive check on dimensions, . Core length, width, and width of edge and end cladding are measured directly from the X-ray film. Plates which do not meet dimensional requirements are rejected. Every 25th plate is radiographed to determine the reproducibility of the process with respect to homogeneity of the dispersion.

This inspection step also includes the visual inspectlon of the fuel plates. The surfaces are inspected for defects. Indentations, pits, rolled in scale and scratches deeper than one thousandth of an inch (0.001 in.) are cause for rejection. Dents and blisters are also cause for rejection.

Safety Hazard: - X-rays are hazardous and over-exposure of the human body will result in severe burns. . Leakage about the machines must be below acceptable levels.: . Regular monitoring by the Health Safety Department is required.

$\checkmark ;-51$ 
Title:

Purpose:

Process:
- Annealing of Fuel Plates and Side Plates

- This specification covers the flatten annealing of cleaned machined plates (stain less steel or stainless clad) (ALCONPE Specification No. C-18) to facilitate assembling into the proper array and to meet plate spacing dimensions in

- the brazed fuel unit. The plates are stack annealed in a clamping jig.

Fuel Plates

Each fuel plate is covered on one side with a thin coat of a mixture containing one part by volume of Fisher Precisionite levigated alumina and ten (10) parts of water. A three (3) inch camel's hair brush is used to apply an even coating. smine coated fuel plates are allowed to dry for at least fifteen (15) minutes.

Approximately twenty-five (25) fuel plates are stacked together with the coated sides adjacent to the uncoated sides. The stack is loaded in a jig composed of two platens bolted together to clamp the plates. The inner surfaces of the two platens are coated with a mixture containing one part by volume Fisher levigated alumina and ten parts water. The loaded and tightened assembly is dried in an oven at three hundred thirty degrees Fahrenhelt $\left(330^{\circ} \mathrm{F}\right)$ for a minimum of sixteen (16) hours.

This assembly is annealed in a leak tight muffle furnace using a hydrogen atmosphere from a leak tight feed line at twenty-one hundred degrees Fahrenheit plus or minus twenty-five degrees Fahrenheit $\left(2100^{\circ} \mathrm{F}+25^{\circ} \mathrm{F}\right)$. A hydrogen dewpoint of minus eighty degreès Fahrenheit $\left(-80^{\circ} \mathrm{F}\right)$, as measured by an accurate dewpolnter at furnace inlet, must be maintained. The load is charged into the furnace held at under five hundred and seventy degrees Fahrenheit (570 $\left.{ }^{\circ} \mathrm{F}\right)$.

CAUTION - A dried inert gas purge must be used inthe furnace until a temperature of twelve hundred degrees Fahrenheit $\left(1200^{\circ} \mathrm{F}\right)$ is reached to avoid the possibility of attaining an explosive mixture of hydrogen and air. The temperature is raised to twelve hundred degrees Fabrenheit $\left(1200^{\circ} \mathrm{F}\right)$ at the rate of five hundred forty degrees Fahrenheit $\left(540^{\circ} \mathrm{F}\right)$ per hour. At this temperature, the inert gas atmosphere 
is replaced by hydrogen. A flow rate sufficient to bright anneal stainless steel is required. The temperature is ralsed to tweoty-one hundred degrees Fahrenheit $\left(2100^{\circ} \mathrm{F}\right)$ at a rate of approximately five hundred and forty (540) degrees per hour. The plates are held at twenty-one hundred degrees Fahrenheit (2100\%) for two hours, and then furnace cooled to approximately five hundred seventy degrees $\left(570^{\circ} \mathrm{F}\right)$. At this temperature, the hydrogen atmosphere is replaced with a inert gas purge. The assembly is then removed from the furnace and air cooled. After disassembly, the fuel plates are scrubbed under flowing water to remove the alumina. Care is exerted in this scrubbing treatment to avoid distortion of the plates.

\section{Side Plates}

Grooved side plates are annealed as above with the following exceptions:

1. The individual side plates are separated by type $304 \mathrm{~L}$ stainless steel shim stock approximately thirty thousandths of an tnch thick (0.030 in.).

2. The alumina mixture is applied to both sides of the shim stock. The side plates are not coated because of the difficulty in removing the alumina from the grooves.

3. A maximum of fifteen side plates are stacked with the alumina-coated shims between each plate.

Equipment: " Furnace capable of attaining (at a controllable rate not exceeding $540^{\circ} \mathrm{F} / \mathrm{hr}$ ) and holding $2100^{\circ} \mathrm{F}+25^{\circ}$ with hydrogen atmosphere of $-80^{\circ} \mathrm{F}$ dewpoint and heliüm source.

Accurate dewpoint measuring instrument.

Safety: $\quad-\quad$ CAUTION - At temperatures under twelve hundred degrees - Fahrenheit $\left(1200^{\circ} \mathrm{F}\right)$, hydrogen will form violently explosive mixtures with air; therefore, purging of furnaces under this temperature must not be done with hydrogen gas.

¿ 03 
Title:

Purpose:

Process:
- Final Inspection of Fuel Plates

- This specification covers the inspection of finished stainless steel clad fuel plates prior to cleaning and assembly into a fuel element.

- The fuel plates are visually inspected. Oxide indentations, pits, and/or scratches deeper than one thousandth of an inch ( 0.001 in.) are cause for rejection. Dents, blisters, and presence of any foreign material on the surface are also cause for rejection. The fuel plates are dimensionally inspected per the appropriate drawing. 
Title:

Plate Inspection for Alpha Contamination

Purpose:

This specification covers the sampling and alpha counting of cleaned fuel plates, prior to assembly for brazing, to determine the level of surface contamination by Uranium-235.

Process: $\quad$ Sampling - Every tenth plate shall be cleaned and counted.

Counting - The plate shall be checked for alpha contamtnation by means of gas flow proportional counting or a similar approved method. Alpha contamination equivalent to 0.5 micrograms of U-235 per square foot of plate surface shall be the maximum allowable level of contamination. It is assumed that one microgram of U-235 per square foot of surface of the fuel plate is equivalent to 150 disintegrations per minute per square foot of plate surface. In addition the plate identity and amount of alpha contamination will be recorded and this information forwarded to the head of the Health Physics Group of the Contracting Agency or its authorized representative. 
Title:

Purpose:

Process:
- Assembly of Control Rod Fuel Plates into Side Plates

- This specification covers the assembly of fuel plates, combs, and grooved side plates into a fuel assembly. The components are assembled into a jig, braze and stop-off materlal is applied as required, and then the assembly is brazed. The same jig is used for both assembly and brazing; therefore the material used in constructing the jig should have the same expansion characteristics as the component material. Coast Metals N.P. braze metal powder is used for brazing, Colmonoy Nicrobraz cement for binding, and Colmonoy Green Stop-off to restrict the flow of the braze metal onto the fuel plate.

a. Two side plates, with grooved sides facing each other, are placed inside the supports of the open-end-up Ushaped jig and centered longitudinally. The distance between matching groove bottoms should provide for the fuel plate width and five thousandths of one inch ( 0.005 in $_{\text {; }}$ ) braze metal clearance at each edge between the fuel plate and groove bottom. To allow for flexibility in assembly, the inside dimension of the " $U$ " supports is normally about, 100 inch larger than the finish width of the assembly. A shim plate is used between each side of the jig and the side plate to compensate for the gap. A stop, usually a removable comb holder, is used at one end of the jig to position the comb and fuel plates. Stops on the front $U$ yoke position the side plates.

b. A short fuel plate is inserted from the open end of the jig into the bottom groove of the side plates and positioned snugly against the comb hoider and the plate inserted into the bottom groove of the comb.

c. The jig is tilted about the longitudinal axis approximately twenty degrees $\left(20^{\circ}\right)$.

d. The dry Coast Metals N.P. braze metal is applied to the plate joint by gravity from a stainless steel pointed tube resembling the barrel of a mechanical pencil. It is important that the braze metal be confined to the inactive

$\ddot{45}-56$ 
edge of the fuel plate and not preplaced on the cladding surface above the fuel core. Since the minimum specification of the width of the inactive stainless steel edge of the fuel plate is one-tenth of an inch $(0.100 \mathrm{in}$.), and twenty-five thousandths of an inch (0.025 in.) is the maximum distance the plate is inserted in the plate groove, only a seventy-five thousandths of an inch (0.075 in.) wide strip of inactive stainless steel remains for preplacement of braze powder. It is recommended that the width occupied by the braze powder be less than sixty thousandths of an inch $(0.060 \mathrm{in}$. $)$.

e. The dry braze metal powder ts cemented into place with Colmonoy Nicrobraz Cement. A nineteen (19) gauge hypodermic needle on a tive cubic centimeter (5 c.c.) syringe is used to apply the cement to the fuel plates adjacent to the braze metal fillet. The cement is allowed to dry for thirty seconds $(30 \mathrm{sec}$ ).

f: A one-quarter inch (1/4 in.) wide strip of Colmonoy Green Stop-off is applied with a camel's hair brush directly adjacent to the braze metal on the active portion of the fuel plate. The stop-off is used to prevent the braze metal from flowing laterally onto the stainless steel cladding of the active core section during the subsequent operation.

g. The jig is tilted about the longitudinal axis in the direction opposite step "c" and the above steps are repeated for the opposite fuel plate to side plate joint. The braze materlals are applied to one side of the fuel plate only.

h. A second short plate is inserted in the second row of side plate grooves and firmly placed in the comb groove.

1. Steps " $\mathrm{d}$ " to "g" are repeated with the addition of filling the comb-to-plate joint with braze metal, cement, and stop-off.

j. The process is repeated, inserting plates from bottom until 4 plates have been inserted.

k. The first long plate is then inserted and steps " $\mathrm{d}$ " to " $\mathrm{g}$ " are repeated. The slot in the long fuel plate is to be at the back of assembly. 
1. Six.more short plates are inserted and steps " $\mathrm{d}$ " to " $\mathrm{g}$ " repéated.

$m$. The second long fuel plate is inserted as in " $\mathrm{k} "$.

n. Four more short fuel plates are inserted and steps "d" to "g" are repeated.

o. The second comb is attached to the unit. Comb-fuel plate joints are filled with braze metal, cement, and stop-off.

p. The comb holder is removed from the jig.

q. The fuel assembly is assigned a number and the relative positions of the fuel plates within the fuel assembly are recorded.

CAUTION:

a. Care must be exercised to avoid the application, flow, and/or contamination of the cladding surfaces over the fuel core by the braze metal. The brazing metal shall be free of boron. Shim stock or jig areas that come in contact with the fuel element shall be coated with etther Colmonoy Green Stop-off or Fisher Precisionlte levigated alumina that will act as the separating agent.

b. The suppressor bearing ends of the fuel plates are positioned at the gusset end of the grooved side plates i. e., the handle or top end of the fuel element. 
ALCO-NPE Specification No. FE-32

Title:

Purpose:

Process:
- Brazing of Fuel Assemblies

- This specification covers the brazing of the fuel assembly.

- Brazing of fuel elements is accomplished in a furnace equipped with a leak tight muffle for maintaining a dry hydrogen atmosphere and capable of maintaining a maximum gradient of five degrees Fahrenheit $\left(5^{\circ} \mathrm{F}\right)$ along the entire fuel assembly length at the brazing temperature.

Calibrated chromel-alumel thermocouples are attached (one to the front and the other to the rear) to the assembly. Each thermocouple is checked at room temperature prior to acceptance. The hot junctions are positioned two inches (2 in.) in from the ends of the short fuel plates. One Junction is placed at each end of the fuel element between the middle two fuel plates.

Stainless steel heat baffles should be used around the charge to minimize temperature gradients during the heating and cooling cycle. The jig containing the fuel assembly, complete with thermocouples, is placed in the furnace at a maximum temperature of five hundred seventy degrees - Fahrenhelt $\left(570^{\circ}\right.$ F). A dry inert gas atmosphere, with a minimum dewpoint of minus forty degrees Fahrenheit $\left(-40^{\circ}\right.$ F) as measured by an accurate dewpoint measuring instrument at the inlet, is introduced. Stainless steel thermal reflector shields may be used at the ends of the jlg to minimize thermal gradients along the length of the fuel element.

The furnace temperature is raised to twelve hundred degrees Fahrenheit $\left(1200^{\circ} \mathrm{F}\right)$ at a rate not to exceed three hundred seventy degrees $\left(370^{\circ} \mathrm{F}\right)$ per hour. The furnace Is held at this temperature until the temperature gradient as measured by the work thermocouples, is less than fortyfive degrees Fahrenheit $\left(45^{\circ} \mathrm{F}\right)$. At this time, dry hydrogen with a dewpoint of at least minus eighty degrees Fahrenhelt $\left(-80^{\circ} \mathrm{F}\right)$ is introduced and the inert gas purge discontinued.

(The furnace temperature is raised to eighteen hundred thirtyfive degrees Fahrenheit $\left(1835^{\circ} \mathrm{F}\right)$ and held until the gradient, at the work thermocouples, is less than eighteen degrees Fahrenheit $\left(18^{\circ} \mathrm{F}\right)$ and the outlet hydrogen dewpolnt is at least minus fifty degrees Fahrenheit $\left(-50^{\circ} \mathrm{F}\right)$. The furnace temperature is raised to two thousand ten degrees Fahrenhett 
$\left(2010^{\circ} \mathrm{F}\right)$ and held until the fuel assembly temperature gradient is less than five degrees Fahrenhelt $\left(5^{\circ} \mathrm{F}\right)$. Above this temperature, the furnace temperature is raised slowly by careful manual control. Temperature readings are taken on both thermocouples every minute. The temperature gradient is maintained as low as possible, with a maximum of five degrees: $F$ ahrenheit $(50 \mathrm{~F})$. When the work thermocouple temperatures reach two thousand seventy-one degrees: Fahrenheit $(2071 \% \mathrm{~F})$, the furnace is shut off. The total time for the load above two thousand sixty-six degrees Fahrenheit. $\left(2066^{\circ} \mathbf{F}\right)$; as measured by the thermocouples, should not exceed el ght minutes ( $8 \mathrm{~min}$ ). The brazed fuel assembly is furnace cooled to five hundred seventy degrees Fahrenheit $\left(570^{\circ} \mathrm{F}\right)$, at which temperature, the furnace atmosphere is replaced with an inert gas purge. After thorough purìing; the furnace is opened and the assembly is removed from the furnace and air cooled to room temperature.

After the brazing operation, each assembly is identified with numbers approximately one-half inch (1/2 in.) high. A Burgess Electric. Vibro Tool with a tantalum-carbide tipped point is used for marking. The fuel assemblies are marked with the assigned number on a side plate near the top end and near the top side of the fuel assembly. The last fuel plate inserted determines the top of the fuel assembly.

Equipment: $\quad-$ Hydrogen atmosphere furnace $w 1$ th a $5 \% \mathrm{~F}$ maximum temperature gradient in the working zone, and capable of attaining and maintaining, at the above rates, the brazing temperature. Hydrogen atmosphere of $-80^{\circ} \mathrm{F}$ dewpoint, and inert. gas purge.

Safety: $\quad-\quad$ CAUTION: At temperatures under twelve hundred degrees Fahrenheit $\left(1200^{\circ} \mathrm{F}\right)$, hydrogen will form violently explosive mixtures with air; therefore, purging of furnaces under this temperature must not be done with hydrogen gas. 
Title: $\quad$ - Cleaning of Brazed Fuel Assembly

Purpose: $\quad-\quad$ This specification covers the cleaning of brazed fuel assemblies (ALCO-NPE Specification No. 32) to remove the stop-off residue that was used to avoid the indiscriminate spreading or flowing of brazing material during the furnace brazing operation.

Process: $\quad-\quad$ The fuel assemblies are scrubbed under water with stainless steel brushes. The residue is scrubbed from the water channels using a one-eighth inch $(1 / 8 \mathrm{ln}$.) diameter stainless steel brush. Extreme care must be exercised to avold damage to the fuel plate cladding by scratching, nicking, or removal by the abrasive action of the wire brush. Extreme care must also be exercised to avoid mechanical distortion of the fuel assembly or fuel plates for this will result in failure to meet subsequent dimensional inspection requirements. 
ALCO-NPE Specification No. FEI-34

Revision A- April 1, 1960

Title:

Purpose:

Process:
- Inspection of Brazed Fuel Assembly

- This specification covers the inspection of clean, brazed fuel assemblies (ALCO-NPE Specification No. 33). The fuel assemblies are visually and dimensionally inspected. Place spacing inspection must be performed at this time.

- Visual Inspection - The brazed joints and the fuel plates are visually inspected for splatter, lateral spread of braze metal, pitting, and braze discontinuity.

1. A total of two inches ( $2 \mathrm{in}$.) of void th the braze joints of a fuel plate will be allowed. A void is defined as any area in which the braze metal is not at least flush with the inner surface of the side plates. The presence of voids in excess of the above amount is cause for rejection.

2. Braze runout on any fuel plate in excess of sixty-three thousandthe of an inch (0.63 in.) from the inner surface of the side plates is cause for rejection.

3. Braze metal splatter or pitting over the active core section is cause for rejection.

4. Any pitting or wash of the fuel plate caused by reaction with the braze metal in excess of one thousandth of an inch deep (.001 in.) is cause for rejection.

Dimensional Inspection - The brazed fuel assemblies are dimensionally inspected for squareness, width, water channel spacing, and sag or distortion of top and/or bottom plates. The data are recorded on an appropriate inspection form.

Plate spacings are measured longitudinally at the middle of the fuel plates at one inch (1) in.) stations, beginning at the numbered end. Top and/or bottom plate sag or distortion ts measured at corresponding stations by measuring the distance from the side plate edges to the surface of the fuel plates. Maximum allowable deviation is plus or minus ten per cent $( \pm 10 \%)$ of the nominal spacing. Deviations

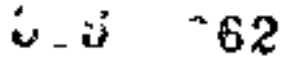


greater than the allowable are cause for rejection.

Air gauging to measure the spacings is not acceptable. A mechanical measuring device incorporating a calibrated elliptical probe has been used successfully. A steel ellipsoid, having one-tenth inch $(0.100$ in.) minor and one hundred fifty thousandths of an inch $(0.150 \mathrm{in}$. major axes, is mounted on the end of a one-tenth inch (0.100 in.) diameter tube approximately twenty-seven inches (27 in.) long. A one-tnch thick plastic block, three (3) inches by six (6) inches, with a hole in the center allowing tube rotation, is mounted near the other end of the tube. A needle indicator is rigidly mounted on the tube, near the plastic block, parallel with the ellipsoid major axis. The needle is calibrated by rotating the ellipsoid between gauge blocks and the width of the space between gauge blocks on a piece of polar graph paper. The calibrations are fastened to the face of the plastic block.

The width of the assembly is measured with a three (3) inch micrometer at six locations along the top and bottom of the side plates for a total of twelve measurements per assembly. Measurements are taken at distances of one (1), stx (6), eleven (11), sixteen (16), twenty-one (21), and twenty-four (24) inches from the numbered end of the element. Failure to meet the specified width conditions is cause for rejection, unless specifically approved by the Contracting Agency or its authorized representative.

Equipment - Water channel spacing probe and inspection equipment 
ALCO-NPE Specification No. A-46

Title: $\quad$ - Handle $P$ in Attachement

Purpose: $\quad-\quad$ This spectication covers the attachment of the handle pin to the gusset plates. This completes the handle used for supporting the fuel element during nuclear reactor refueling.

Process: . - The finish machined handle pin is positioned in the holes provided in the gussét plates and heliarc welded in posttion.

Equipment: - Heliarc welder. 
Title:

Purpose:

Process:
ALCO-NPE Specification No. FEX-47

- Final Inspection of Completed Control Rod Fuel Element

- This spectfication covers the dimensional inspection of completed fuel elements (ALCO-NP E Specification No. A-46). The fuel element is subsequently cleaned, check-ed by the Health Physics Department for surface contamination and packaged for shipment.

Gross distortion of the completed fuel elements is checked by passing the element through a go-no-go box approximately ten per cent (10\%) longer than the fuel element, with inside dimensions equal to the 'maximum free path allowable as shown in the fuel element drawing. The fuel element must pass freely through this box for acceptance. 
Title: $\quad-\quad$ Preparation of Fuel Elements for Shtpment.

Purpose:

- :This specification covers the chemical cleaning, checking for contamination, and packaging for shipment of the finished fuel elements (ALCO-NPE Specification No. FEI-42):

Process:

If it: is necessary to clean the surfaces of the fuel elements prior to shipment, the cleaning operation should be conducted in an area removed from the fuel fabrication plant and relatively free from airborne activity due to fissionable material: All units are to be pickled in warm ten per cent (10\%) nitric acid $\left(\mathrm{HNO}_{3}\right)$ - water $\left(\mathrm{H}_{2} \mathrm{O}\right)$ solution for ten minutes (10 min.), rinsed in hot running water and dried. Immediately after rinsing, the fuel elements are checked by. the Health Physics Department for cleanliness and, if acceptable, each is wrapped in a heavy dry paper and enclosed in a plastic sheath which must be thermally sealed to protect the contents from the atmosphere. The components are then packaged in suitable shipping containers which are designed to protect the units against damage or contamination during storage and shipment. 


\section{ALCO-NPE Specification No. CM-14A}

Title:

Purpose:

Material:

\section{Chemistry:}

- Cladding Material - Type 347 Low Cobalt Low Tantalum

- This specification covers the material used for cladding, frames, combs, dowels and side plates.

- The surfaces shall be free of laps, seams, scabs, or other tnjurious defects. The material shall be sound and free of undue stringers, entrapped foreign materials, gases or. items detrimental to the continuity and strength of the cladding.

- This steel is AISI Type $\mathbf{3 4 7}$ having the chemistry limits set forth in ASTM A-240-58T except that the cobalt shall be 0.025 maximum and tantalum shell be 0.01 maximum.

Chemical Composition:- in wt. \%

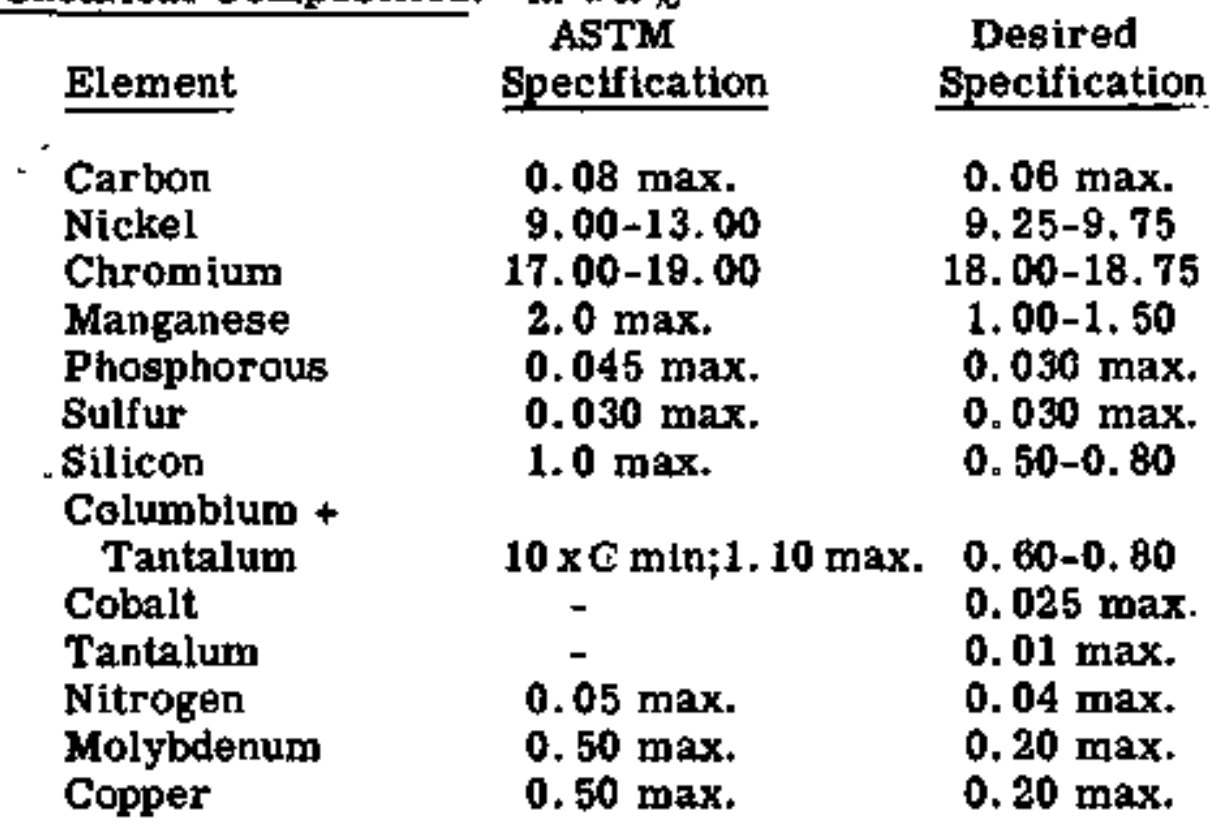

The material with the above composition limits will be used for inert gas shielded tungsten arc welding without filler metal. In addition to meeting the chemical restrictions set forth in this spectication, the delta ferrite content of this material, as calculated from the Schaeffler Constitution Diagram shall be a minimum of $2 \%$ and a maximum of $10 \%$.

In calculating the delta ferrite content from the Schaeffler Constitution Diagram, the following multiplying factors shall be used in computing the chromium and nickel equivalents for the production order: - 


$\begin{array}{ll}\text { Element } & \text { Factor } \\ \text { Carbon } & \\ \text { Manganese } & 30 \\ \text { Silicon } & 1 / 2 \\ \text { Chromium } & 1-1 / 2 \\ \text { Nickel } & 1 \\ \text { Cb+Ta } & 1 \\ \text { Nitrogen } & 1 / 2 \\ \text { Copper } & 30 \\ \text { Molybdenum } & 2 \\ \text { M } & 1\end{array}$

In the event that the chemistry of the heat ts outside the range of the desired specification, but within the ASTM chemistry, and contains a delta ferrite content in the range of 2 to $10 \%$ as calculated from the Schaeffler Diagram, the heat will be acceptable.

In the event the chemistry is outside the desired specification limits, and below the lower limit of $2 \%$ delta ferrite, a weldability test shall be made without filler addition. Freedom from cracking shall consider the heat acceptable. The type and details of the welding test shall be as mutually agreed upon between.Allegheny Ludlum and Alco Products, Inc. Material that is not weldable, as determined by this test will not be acceptable.

Inclusion Content: The inclusion content of this material in the form of $1^{\text {" }}$ thick sheet bar as determined by Method "B" set forth in ASTM E-45-51 shall be equal to or better than an inclusion rating of (12-512). This rating as determined by method " $B$ " shall be comparable to the following method "A" rating: -

Inclustion Type

Type $\cdot A$ (Sulfide)

Type B (Alumina)

Type C (Silicate)

Type D (Globular Oxide)
Thin Series

2

$2-1 / 2$

3

3
Heavy Sertes

$1-1 / 2$

2

3-1/2

2

The thickness of the inclusions found in $1^{\prime \prime}$ thick sheet bar shall not be any greater than that specified in the Inclusion Chart of ASTM E-45-51 speciftcation. 
ALCO-NPE Speciftcation No. CM-14A (Cont' $\left.\mathrm{d}_{+}\right)$

Physical Properties:-

$\begin{array}{lll}\begin{array}{c}\text { Tensile } \\ \text { Strength }\end{array} & \begin{array}{l}\text {.2\% Offset } \\ \text { Ytrength }\end{array} & \begin{array}{c}\text { \% Elongation } \\ \text { in 2" }\end{array} \\ 75,000 \text { psi } & \begin{array}{l}30,000 \text { psi } \\ 40 \%\end{array} & \end{array}$

Purchase Condition:

- Cold rolled, annealed, and pickled sheared mill plate or sheet.

Certification: - Certification shall be furnished to Alco Products, Inc, . or its authorized representative that all materials used in the fabrication and furnishing of the fuel elements are in accordance with the requirements of these specifications. 
Title: $\quad-\quad$ Attaching Gussets Plate to Grooved Side Plate

Purpose: - - This specification covers the attachment of the stainless steel gusset plates to the grooved face of the side plates (ALCO-NPE Specification No. FP-28). Since they do not interfere with subsequent processing, the gusset plates are welded to the side plates prior to their assembly in the fuel element on account of the lack of accessibility of this area after the fuel element is assembled.

Process: $\quad-\quad$ The gusset plate is machined per the applicable drawing and attached to the grooved face of the side plate by heliarc welding. The shouldered end of the gusset, with the channeled side facing the grooved stde of the stde plate, is centered at the square end of the side plate and held flush with the side plate end by a " $\mathrm{C}$ " clamp. A small spacer bar is placed inside the channel of the gusset plate, between it and the side plate, to avoid deformation of the side plate during clamping. After checking for proper alignment, the gusset plate is hellarc welded using

347 stainless steel filler rod at the four gusset plateside plate joints.

Equipment: - Heliarc Welder. 
ALCO -NPE Specification No. FPI-30

Title: $\quad$ - Comb or Grooved Side Plate Inspection

Purpose: $\quad-\quad$ This specification covers the visual and dimenstonal inspection of finished stainless steel combs or side plates prior to assembly into a fuel element.

Process: $\quad-\quad$ Side Plates - Subsequent to grooving and annealing, each plate is visually and dimensionally inspected. The plate groove depths are determined either by gauge wire with a micrometer or by a thin roller attached to a dial indicator. The groove separations which govern fuel plate spacing in the fuel element are measured with a disc-type micrometer. Failure to meet groove depth, width, and/or separation is cause for rejection.

Combs - Subsequent to machining, comb groove width and location are inspected in the same manner as the grooved side plates.

\section{ALCO-NPE Specification No. FP-6:}

\section{Title: $\quad-\quad$ Comb Machining}

Purpose: $\quad$ - This specification covers the machining of stainless steel combs to be used at the ends of the fuel plates in the fuel elements. The combs are assembled tn the fuel assembly prior to brazing.

Process: $\quad-\quad$ Combs are normally made from 3 in, $x 1$ in, $\pm 1 / 16$ in. material .050 in. $+.003 \mathrm{in}$. thick. The length is milled to final size. The width is milled oversize $(1 / 4$ inch) to provide sufficient stock for holding during the slotting operation. Slotting is performed on a milling machine with a screw-slotting cutter. A group of fifteen (15) or twenty (20) combs is held by the excess material on the width in a precision vise mounted on the table of the milling machine. Each slot is machined individually. After complete slotting, the pieces are mounted in a precision vise and machined to remove the excess width stock.

Equipment: - Milling Machine 
Core Order *

Ho. of Cores Ordered

Urenium Dloxide Bpectilcations per core:

1. Identification

2. Burichment

3. We1ght per cent

4. Grane per core

5. Particle size range

Boron Carblde Specifications per core:

1. Identification

2. Welght per cent

3. Grang per core

4. Particle stze range

stalnlesi steel specifications per core:

1. Identification

2. Welght per cent

3. Grabe per core

4. Farticle size range

Theoretical Total Core Weight, grams

Desired Core stze:

Special Instiuctions:
Order Date

Order Completed 
Deta for Core Order \#

Deviations from the specified core composition or fabrication procedure:

Record of Individual core welght and thlckness: (To be completed unlegs otherwise specified.)

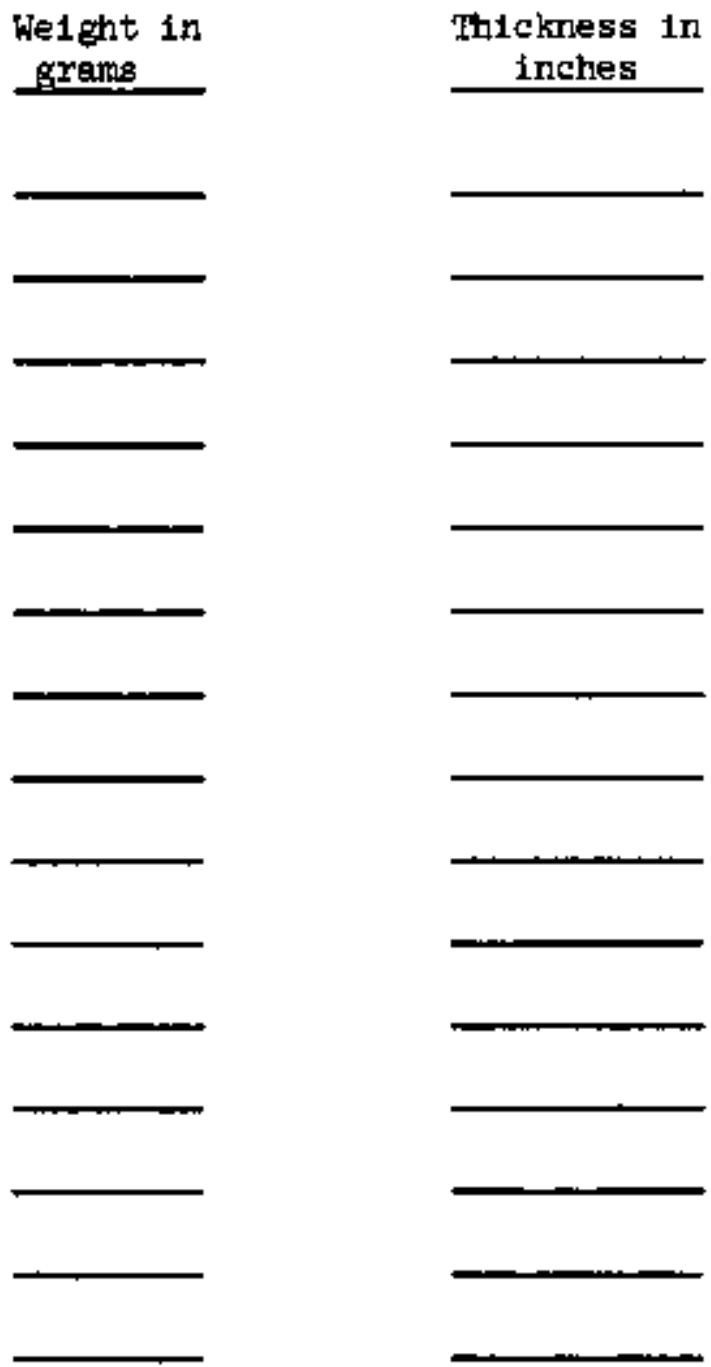

Average Core Welght

Averege Core Ihickness

Thickness in
inches

grams
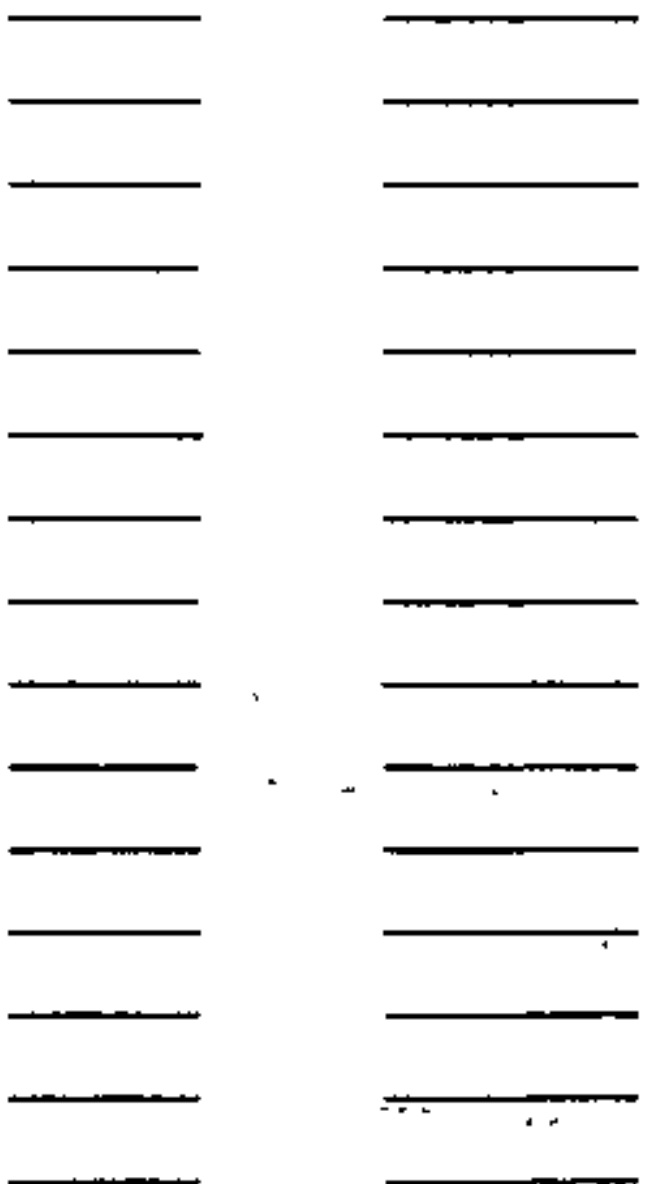
Data for core order \#

\section{A. Blending Operation}

1. Total weight of core components to be batch blended for cores.
a. Uraniưn dioxide: grams.
b. Boron carbide: grains.
c. Stainless steel: grams.

2. Identification of blending container:

3. Blending device to be used:

4. Initial ary blending tioe:

5. Type of alcohol to be added: ; voluge to add:

6. Method of alcohol addition:

7. Alcohol to be added:

8. Final reblending time:

B. Cold Pressing Operation

1. Pressure to be used:

c. Sintering Operation

1. Sinter for hours at ${ }^{\circ} \mathrm{F}$.

D. Colning Operetion

1. Pressure to be used:

E. Other Operations

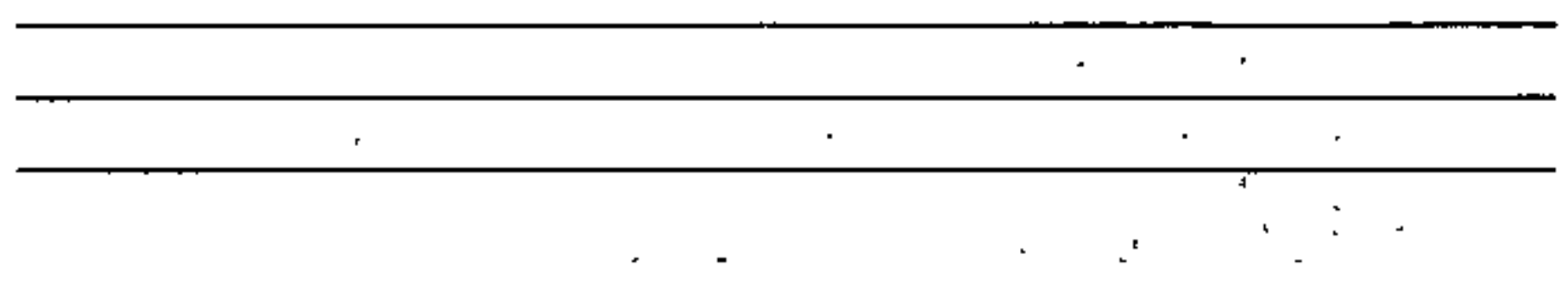


$x+n$

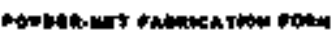

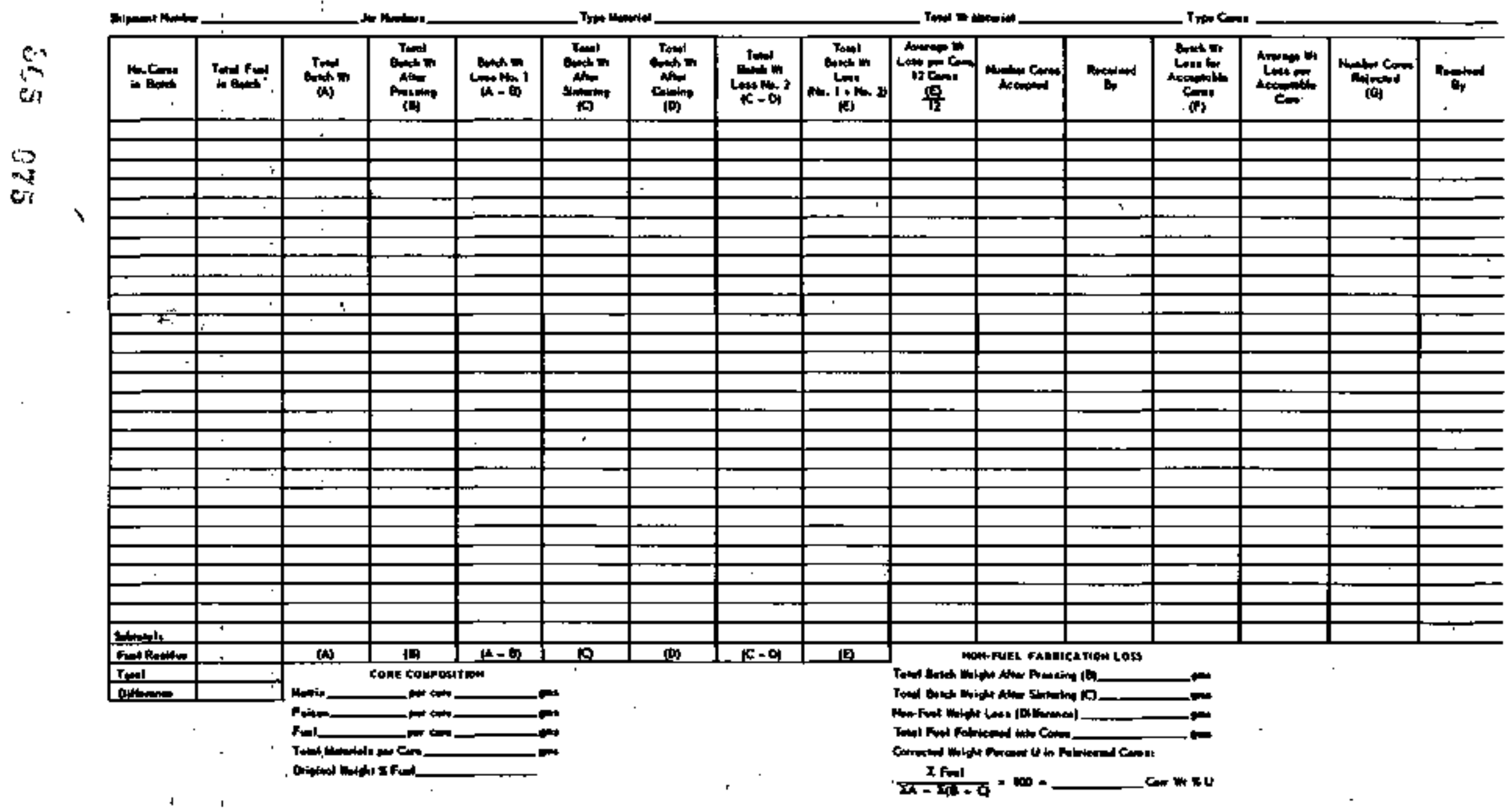




\section{MTr SETHES:}

Totel

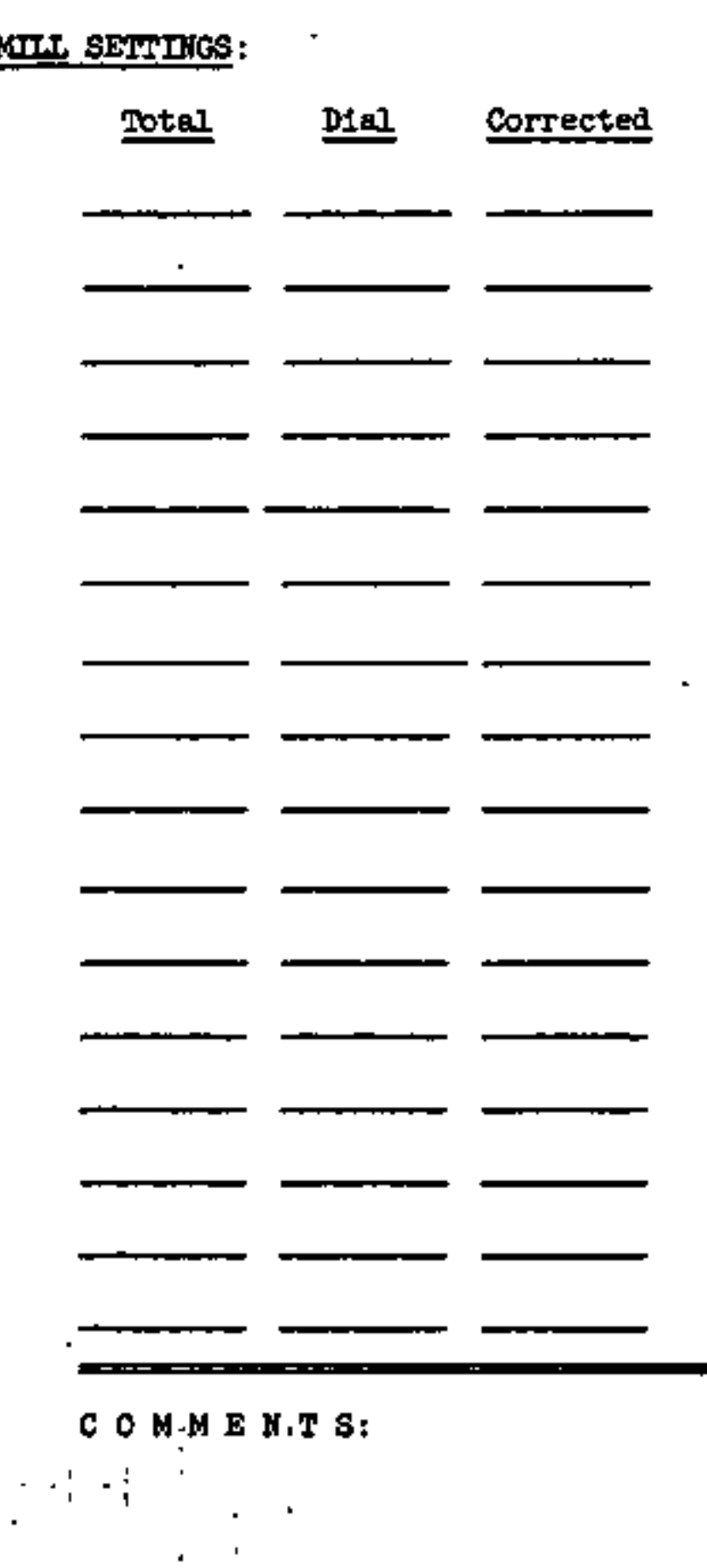

C O M-M E H.T S:

- $1=$

,

i

-

, I.
Sheet Ho.

Date
Plate Mumber

\section{Core Order Mumber}

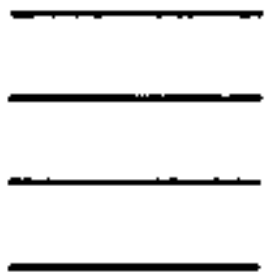

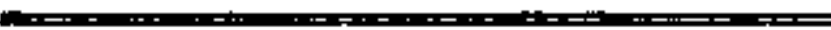

Brame Stze

$\mathbf{x}$

$\mathbf{x}$

Cover Plate Thickneqs

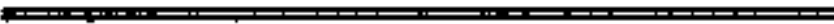

Rolling Tewpersture

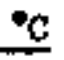

Preheat Time

Minutes..

Reheat THe Minutes.

Roll to Inches.

Reverse Rolling Dtrection: Yes _ـ No Mip Fate Over: Yes ס

'Double Fnd Anneal:

B13et Rolling Drrection:

$$
305 \quad 076
$$


MUEL PLATE FabricatION RECORD

\begin{tabular}{|c|c|c|c|c|c|c|c|c|c|}
\hline \multirow{3}{*}{$\begin{array}{l}\text { PLATE } \\
\text { NO. }\end{array}$} & \multicolumn{2}{|c|}{ TYPE OF FUEL PLATE } & \multirow{3}{*}{$\begin{array}{c}\mathbf{H O}_{2} \\
\text { QरTTCH } \\
\text { No. }\end{array}$} & \multicolumn{5}{|c|}{ DESCRIPTION OF REJECTION } & \multirow{3}{*}{$\begin{array}{c}\text { TRANSFERREC } \\
\text { FOR } \\
\text { BRAZING }\end{array}$} \\
\hline & \multirow{2}{*}{$\begin{array}{c}\text { STATIOHARY } \\
\text { ELEMENT }\end{array}$} & \multirow{2}{*}{$\begin{array}{c}\text { CONTROL ROD } \\
\text { ELEMEN T }\end{array}$} & & \multirow{2}{*}{$\begin{array}{c}\text { HOT } \\
\text { ROLLING }\end{array}$} & \multicolumn{3}{|c|}{ COLO ROLLING } & \multirow{2}{*}{ mISCELLANEOUS } & \\
\hline & & & & & PITs & Bow & LENGTH & & \\
\hline . & & & & & & & & & \\
\hline \multirow{2}{*}{\multicolumn{10}{|c|}{7}} \\
\hline & & & & & & & & & \\
\hline \multicolumn{10}{|c|}{ 范 } \\
\hline & & & . & & & & & & \\
\hline & & & & & & & & & \\
\hline & & & & & & & & & \\
\hline & & & & & & & & & \\
\hline & & & & & & & & $!$ & \\
\hline & & & & & & & & & \\
\hline & & & & & & & & & \\
\hline & & & & & & & & & \\
\hline & & & & & & & & & \\
\hline & & & & & & & & & \\
\hline & & & & & & & & & \\
\hline & & & & & & & & & \\
\hline & & & & & & & & & \\
\hline & & & & & & & & & \\
\hline & & & & & & & & & \\
\hline & & & & & & & & & \\
\hline & & & & & & & & & \\
\hline & & & & & & & & & \\
\hline & & & & & & & & & \\
\hline & & & & & & & & & \\
\hline
\end{tabular}




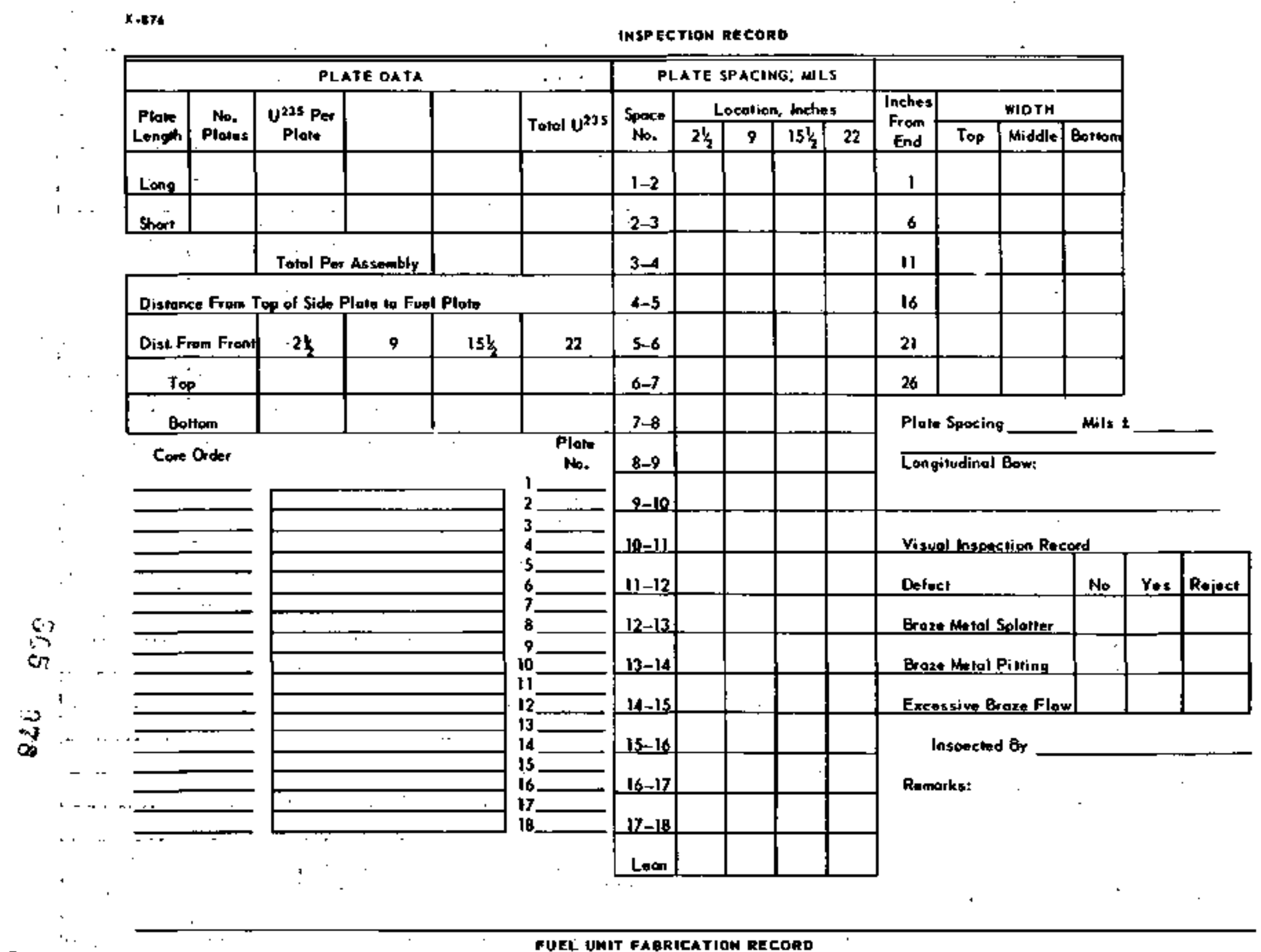

7
Typo Unil Destinotion
Shipped
On Tr. No.
Fuel Unit Number

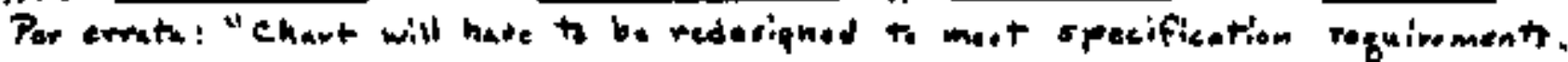


RAOIOGRAPMIC INSPECTION SHEET OF FUEL PLATES

\begin{tabular}{|c|c|c|c|c|c|c|c|c|c|}
\hline \multirow{2}{*}{$\begin{array}{l}\text { PLATE } \\
\text { No. }\end{array}$} & \multirow{2}{*}{$\begin{array}{c}\text { DATE } \\
\text { DELIVERED }\end{array}$} & \multirow{2}{*}{$\begin{array}{c}\text { DATE } \\
\text { RECEIVEO }\end{array}$} & \multirow{2}{*}{$\begin{array}{l}\text { OUALITY } \\
\text { CONTROL } \\
\text { CHECK }\end{array}$} & \multirow{2}{*}{$\begin{array}{l}\text { QUALITY } \\
\text { O.K. }\end{array}$} & \multirow{2}{*}{$\begin{array}{l}\text { MINIMUMM ENO } \\
\text { STAINLESS. INCHES }\end{array}$} & \multirow{2}{*}{$\begin{array}{l}\text { POSSIBLE } \\
\text { EXCESSIVE } \\
\text { BOWINE }\end{array}$} & \multirow{2}{*}{$\begin{array}{l}\text { MNN. EOGE } \\
\text { STAINLESS, } \\
\text { PNCHES }\end{array}$} & \multicolumn{2}{|c|}{ RECOMMENDATION } \\
\hline & & & & & & & & ACCEPTED & REJECTEO \\
\hline & & & & & & & & & \\
\hline & & & & & & & & & \\
\hline \multicolumn{10}{|l|}{ - } \\
\hline & & & & & & & & & \\
\hline & & & & & & & & & \\
\hline & & & & & & & & & \\
\hline & & & & & & & & & \\
\hline & & & & & & & & & \\
\hline & & & & & & & & & \\
\hline & & & & & & & & & \\
\hline & & & & & & & & & \\
\hline & & & & & & & & & \\
\hline & & & & & & & & & \\
\hline & & & & & & & & & \\
\hline & & & & & & & & & \\
\hline & & & & & & & & & \\
\hline & & & & & & & & & \\
\hline & & & & & & & & & \\
\hline & & & & & & & & & \\
\hline & & & & & & & & & \\
\hline & & & & & & & & & \\
\hline & & & & & & & & & \\
\hline & & & & & & & & & \\
\hline & & & & & & & & & \\
\hline
\end{tabular}




\section{SAMPLE CALCULATIONS}

The flux suppressor and matrix powders are specified in terms of europium and stainless steel. Since the europium is in the form of $\mathrm{Eu}_{2} \mathrm{O}_{3}$, it is necessary to determine by calculation the quantity to be incorporated. in each core. Each batch of $\mathrm{Eu}_{2} \mathrm{O}_{3}$ which is treated is analyzed for europlum. It has been found that after htgh firing, the compound is approximately 85 wt. $\%$ ouropium.

a. Data required (values are for illustration purposes only)

Wt. \% Eu in high fired europium oxide

85

Density of europlum oxide

$7.4 \mathrm{gms} / \mathrm{cm}^{3}$

Density of stainless steel

$7.9 \mathrm{gms} / \mathrm{cm}^{3}$

: Grams of Eu per suppressor

$1 \mathrm{gm}$.

Volume of suppressor .068 in. $x \cdot 274$ in. $x 2.180$ in. $\times 16.38 \mathrm{~cm}^{3} / \mathrm{in}^{3}$

Wt. $\% \mathrm{Fe}$ in matrix 71

Wt. \% Ni in matrix

Wt. $\%$ Cr in matrix

b. $\quad$ Europium oxide (gms, required $=$

1.0 (gms. Eu required per suppressor) .85 (Wt. $\%$ Ev in europlum oxide $x$ Efficiency of Addition* $=1.18 \mathrm{gms}$

c. Stainless steel required

Volume of europium oxide $=\frac{1.18 \text { (gms europium oxide) }}{7.4 \mathrm{gm} / \mathrm{cm}^{3} \text { density of europium oxide }}=.16 \mathrm{~cm}^{3}$

Volume of Suppressors=. $068 \mathrm{in} . \times .247 \mathrm{ln} . \times 2.1 \mathrm{in}, \times 16,38 \mathrm{~cm}^{3} / \mathrm{tn}^{3}-.65 \mathrm{~cm}^{3}$

Volume of stainless steel in suppressor $=.64 \mathrm{~cm}^{3}-.16 \mathrm{~cm}^{3}=.48 \mathrm{~cm}^{3}$

Statnless steel (gms, required) $=, 48 \mathrm{~cm}^{3} \times 7.9 \mathrm{gm} / \mathrm{cm}^{3}=3.6 \mathrm{gms}$.

d. $F e(\mathrm{gms}$. required) $=.71 \times 3.8 \mathrm{gms}=2.70 \mathrm{gms}$.

e. $N \mathrm{~L}$ (gms. required) $=.11 \times 3.8 \mathrm{gms}=.416 \mathrm{gms}$.

f. $C r$ (gms. required) $=.18 \times 3.8 \mathrm{gms}=.685 \mathrm{gms}$.

* Efficiency of additions depends on equipment, plant, and personnel. It shall be determined by the manufacturer. 
The fuel, burnable poison, and matrix powders are specified in terms of grams of uranium-235, boron-10, and statnless steel. . Since the fuel is used in the form $\mathrm{UO}_{2}$ and the burnable poison in the form of natural $\mathrm{B}_{4} \mathrm{C}$, it is necessary to determue by calculation the quantities of these materials which are to be incorporated into each core'." Each batch of as-received $\mathrm{UO}_{2}$ is assayed for total uranium content as well as for isotopic concentration of uranium-235.

Likewise, the concentration of boron and boron- 10 in the boron carbide is accurately determined.

Sample calculations illustrating the method utilized in determining the required quantities of $\mathrm{UO}_{2}$ and $\mathrm{B}_{4} \mathrm{C}$ in each fuel plate are listed below.

A. Data required: (Values are for illustration purposes only)

$\begin{array}{lc}\text { Wt. } \% \text { U-235 in U } & 93.07 \\ \text { Wt. } \$ \mathrm{U} \text { in } \mathrm{UO}_{2} & 97.63 \\ \text { wt. } \% \text { B-10 in B (natural) } & 18.09 \\ \text { Wt. } \% \text { B in } \mathrm{B}_{4} \mathrm{C}: & 75.9 \\ \text { gms. U-235 per plate } & 28.62 \\ \text { gms. B-10 per plate } & 0.02581\end{array}$

B. Determination of grams of $\mathrm{vO}_{2}$ per plate:

Grams of $\mathrm{UO}_{2}=28,62(\mathrm{gm} . \mathrm{U}-235)$

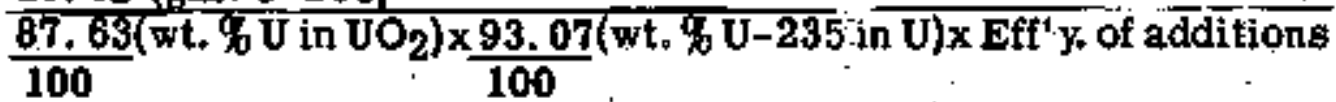
$=35.09$

C. Determination of grams of $\mathrm{B}_{\mathbf{4}} \mathrm{C}$ per plate:

Grams of $B_{4} C=\frac{0.02581(g m . B-10)}{\frac{75.9}{100}\left(w t .5 B \text { in } B_{4} C\right) \times \frac{18,09}{100}\left(w t . \% B-10 \text { in } B_{n}\right) \times E f f^{+} y \cdot \text { of additions }}=0.188$

As might be expected, the final density or the densification factor

(Measured volume ) of the fabricated core material has a significant effect on Theoretical volume)

the charge of stainless steel powder required to meet dimensional specifications in the finished composite plate. 


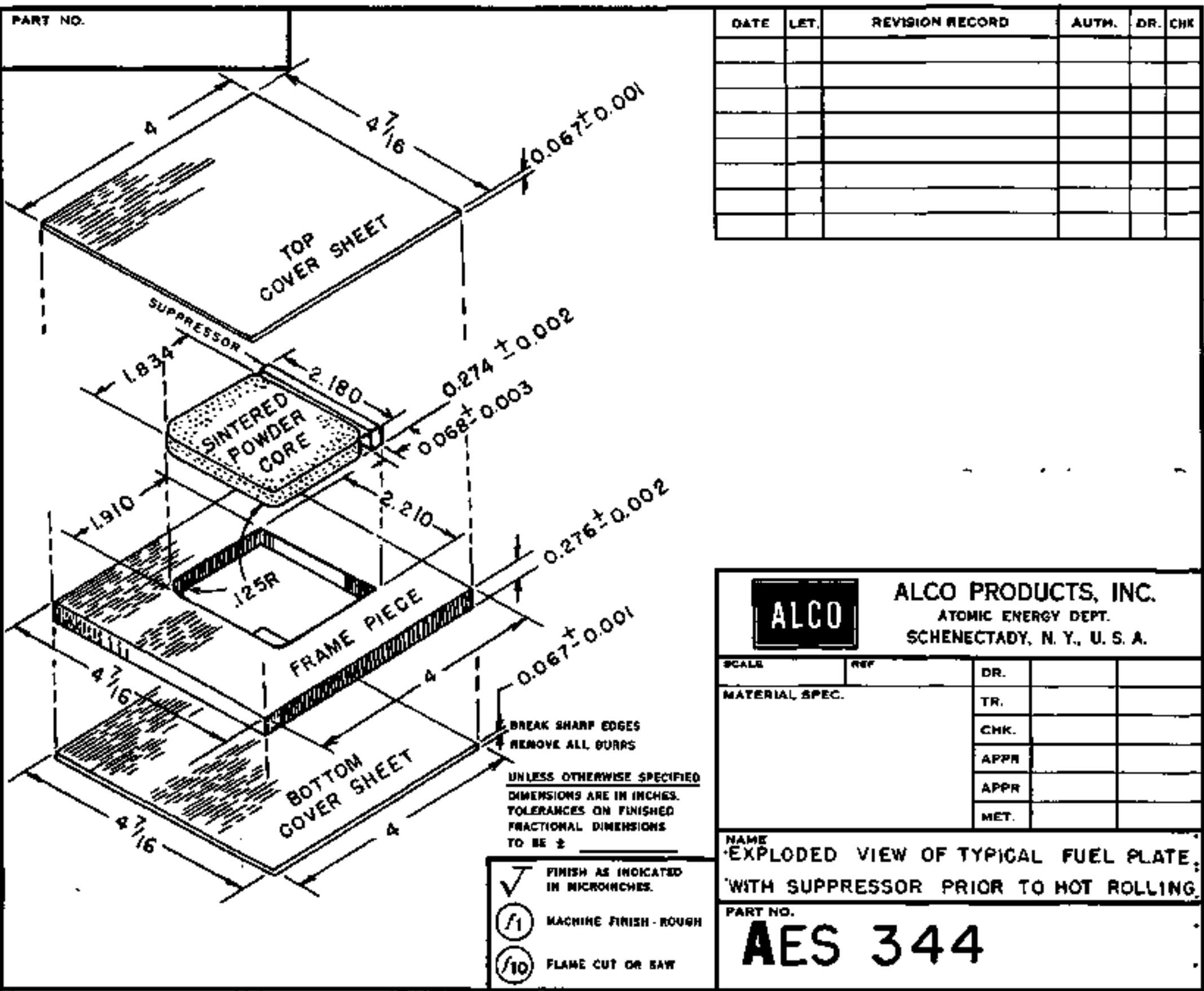




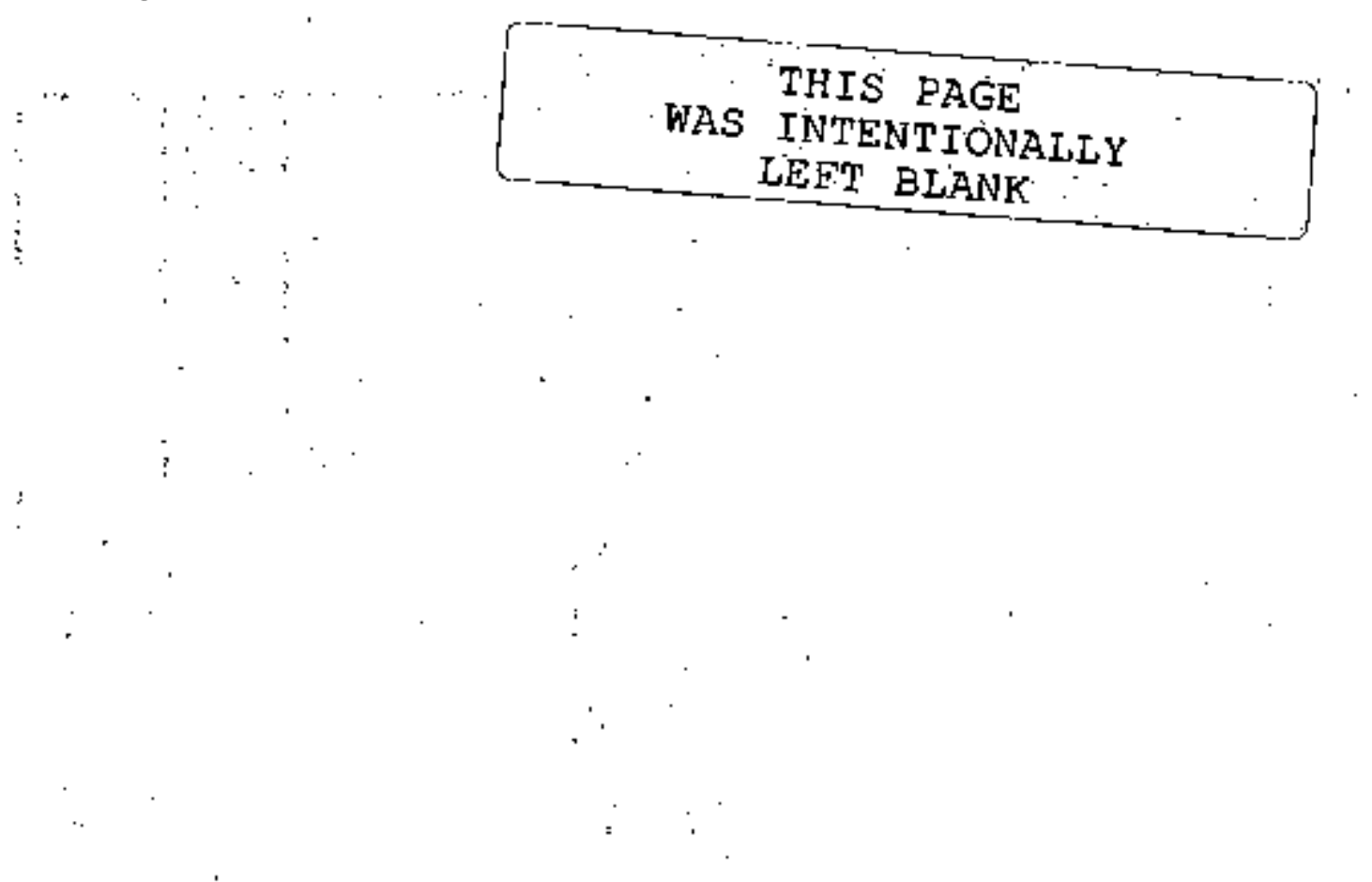




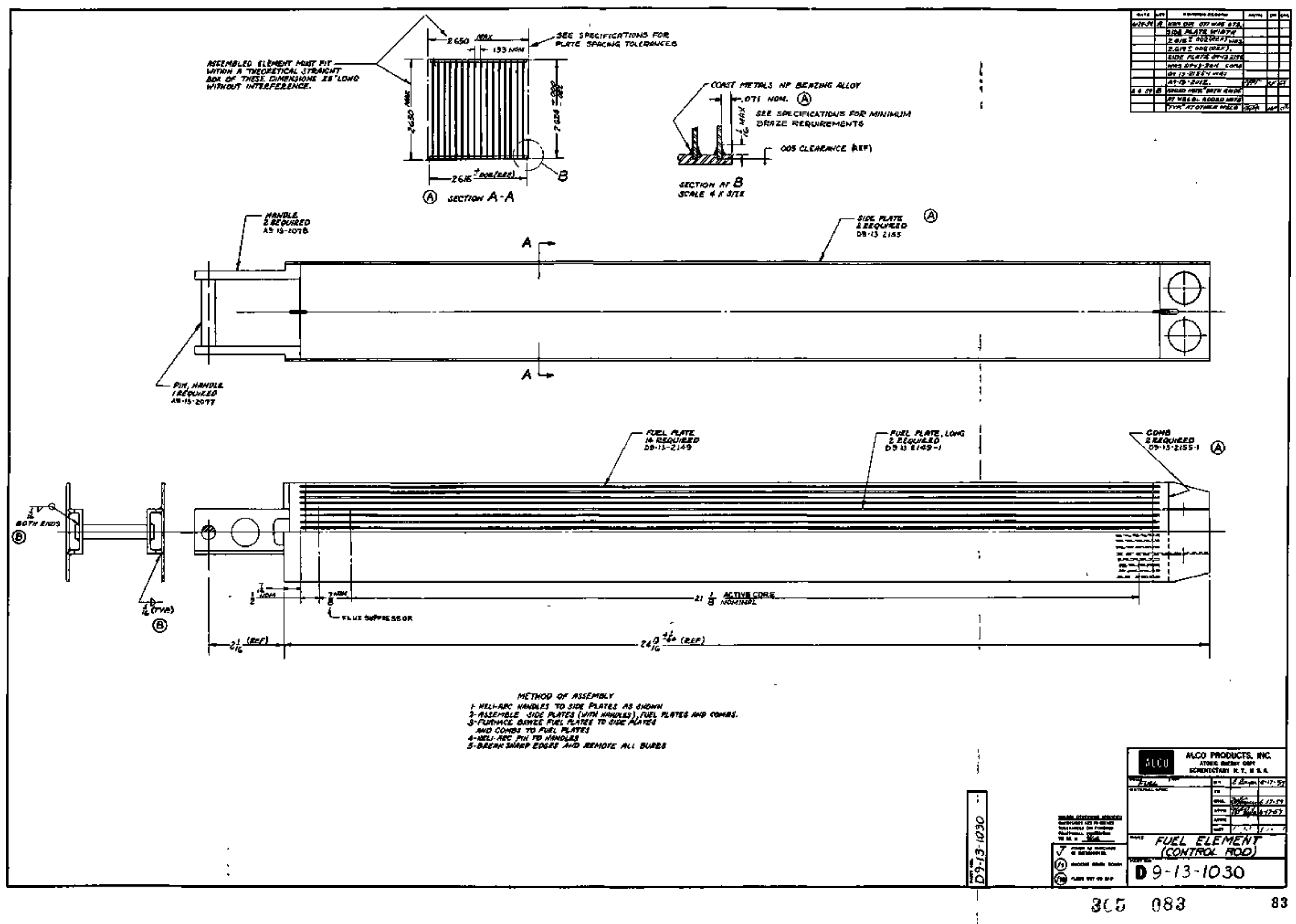



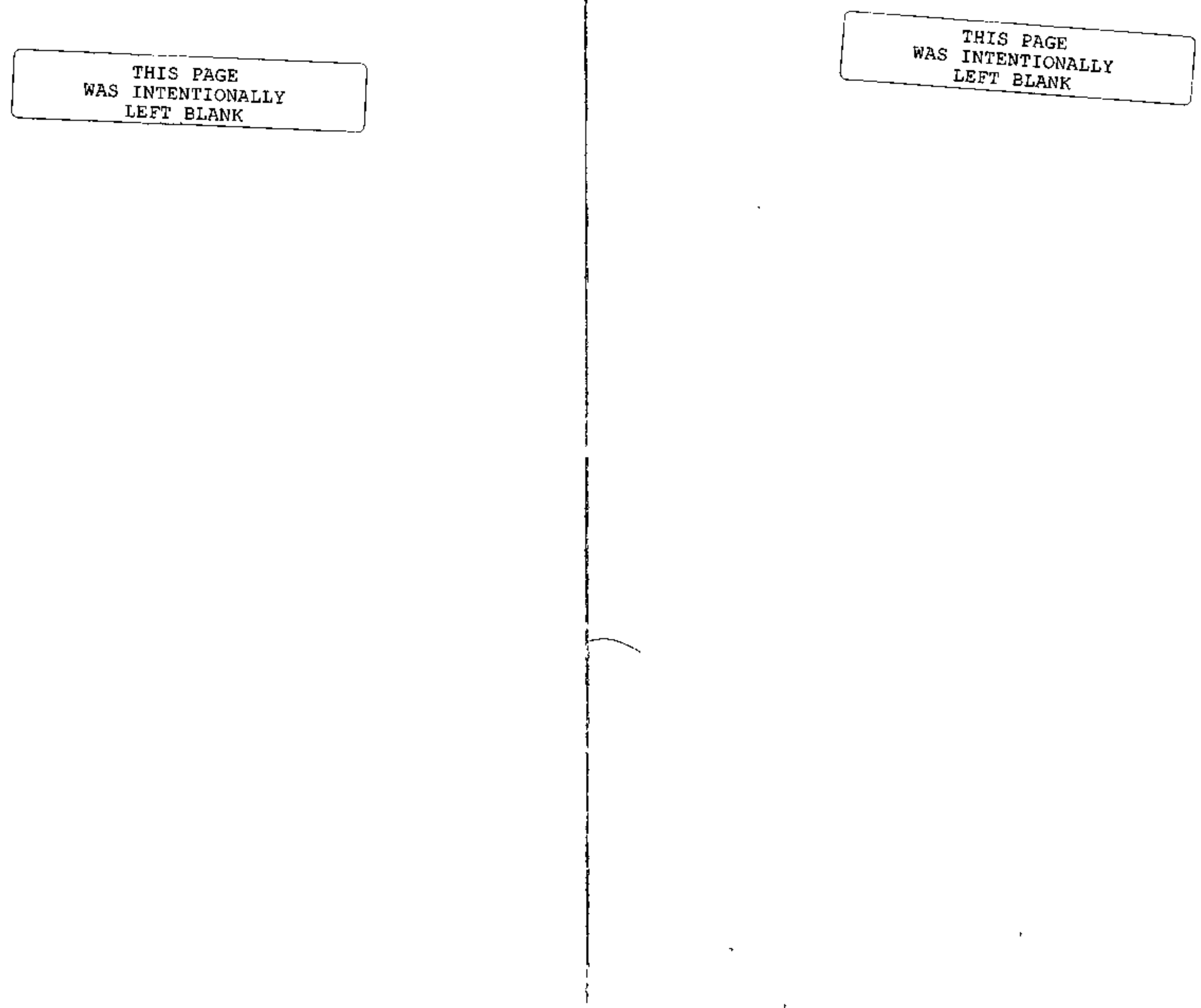


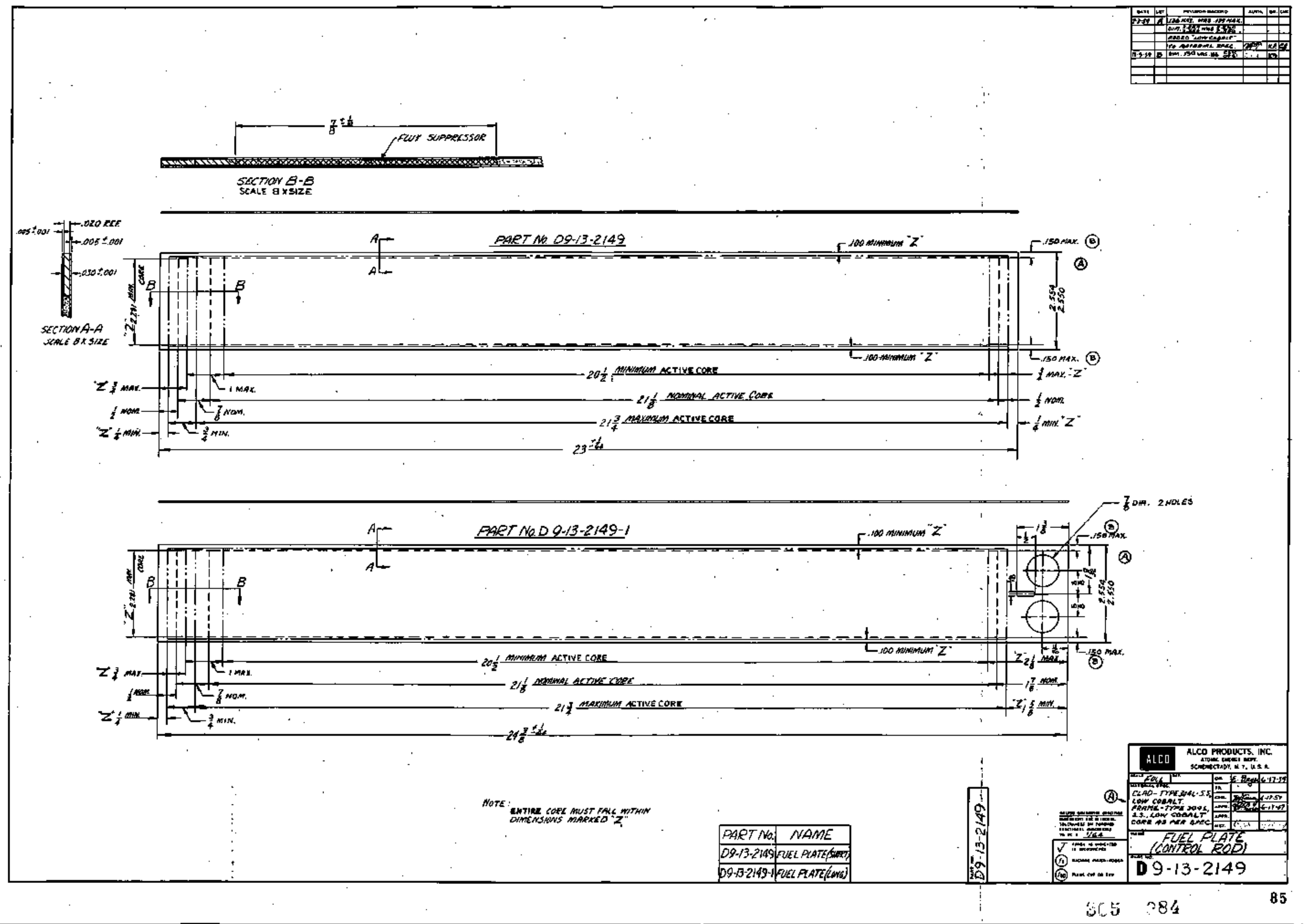





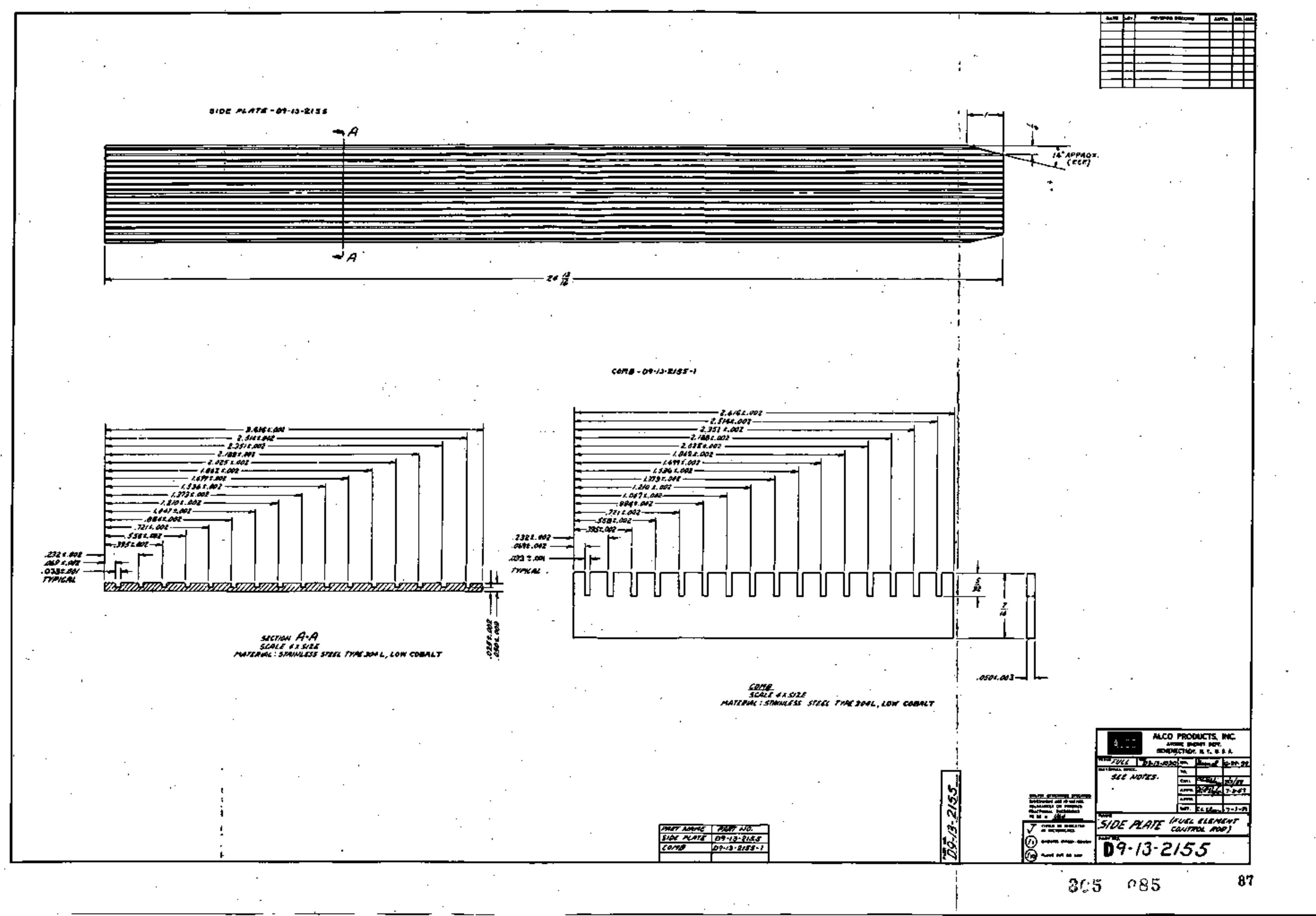




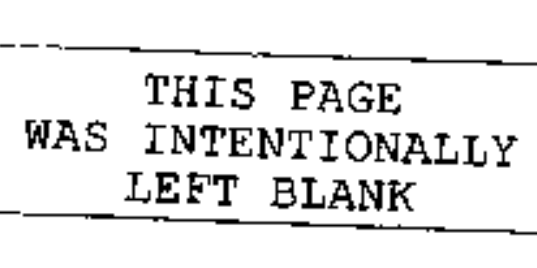




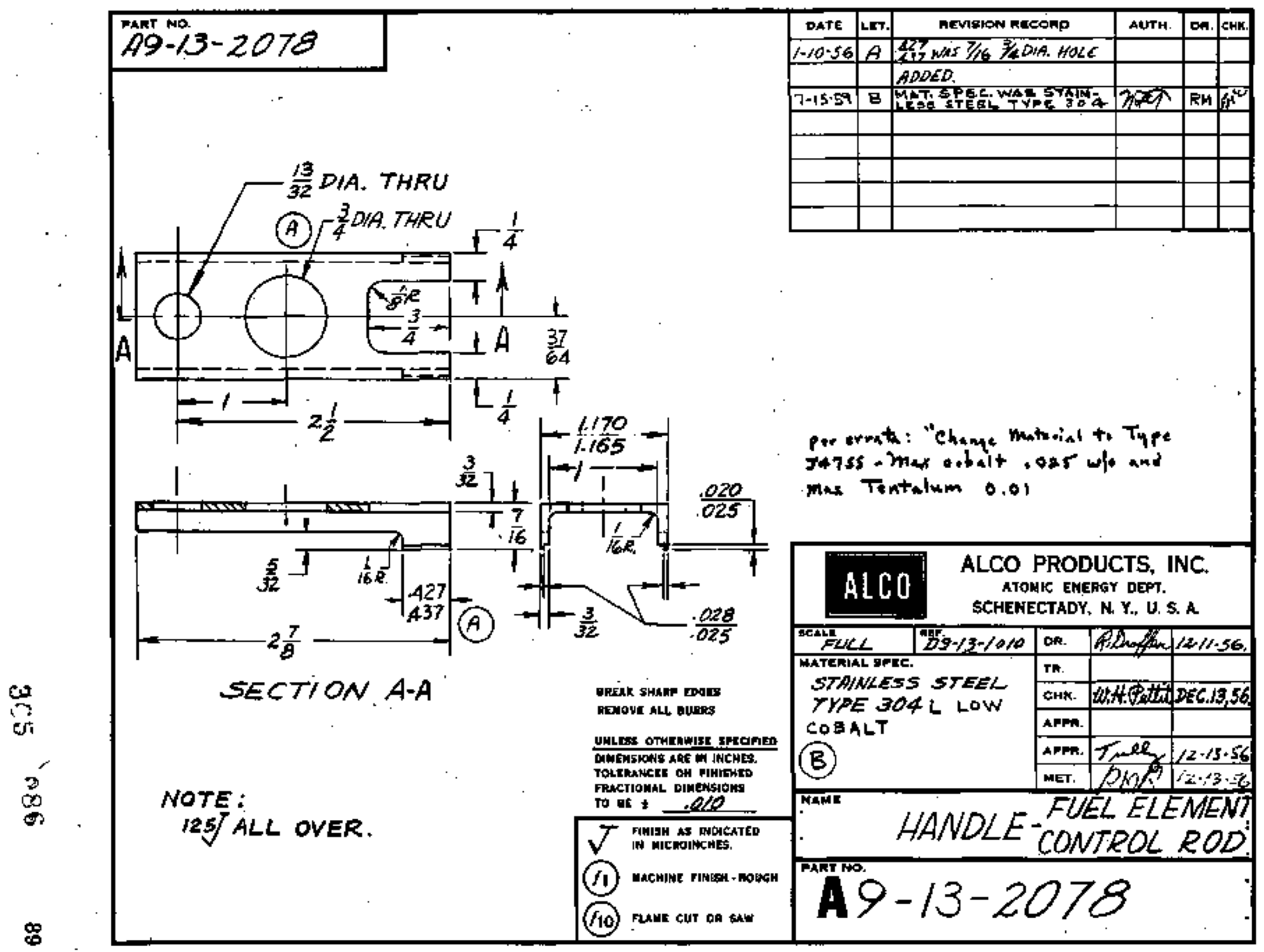




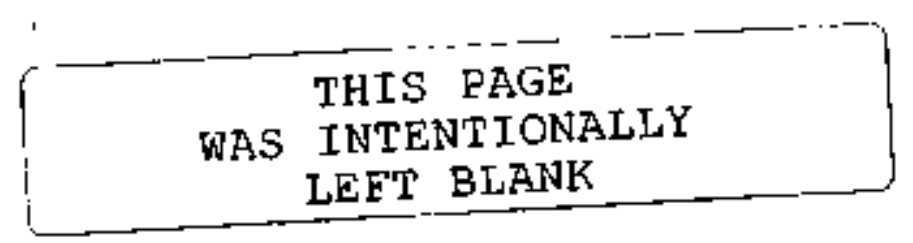




\section{PANT NO. \\ A9-13-2077}

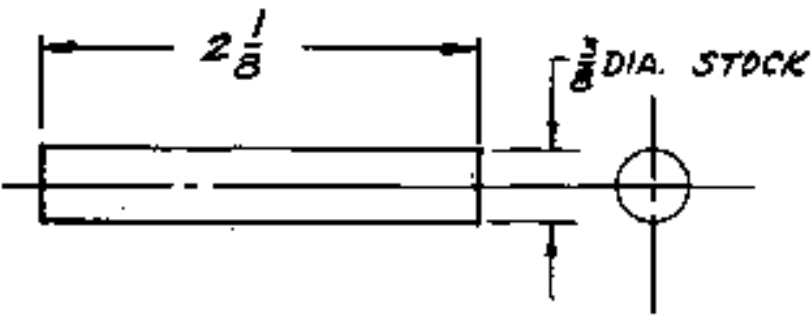

3

(f1) BOTH ENDS.

\begin{tabular}{|c|c|c|c|c|c|}
\hline DATE & Let. & REvisolsw RECORD & AMTH. & Den. & strk. \\
\hline $7-15-59$ & $\mathbf{A}$ & 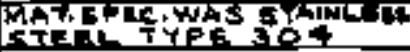 & \%a & $M$ & $\mathrm{fs}^{40}$ \\
\hline & & & & & \\
\hline & & & & & \\
\hline & & & & & \\
\hline & & & & & \\
\hline & & & & & \\
\hline & & - & & & \\
\hline & & & & & \\
\hline
\end{tabular}

\begin{tabular}{|c|c|c|c|c|}
\hline & $\begin{array}{l}\text { ALCO } \\
\text { ATO } \\
\text { SCHEN }\end{array}$ & $\begin{array}{l}\text { PROD } \\
\text { MAC ENE } \\
\text { ECTADY }\end{array}$ & $\begin{array}{l}\text { UUCTS, } \\
\text { ERGY DEPT. } \\
\text {. N. Y, U. }\end{array}$ & $\begin{array}{l}\text { INC. } \\
\text { s.A }\end{array}$ \\
\hline & 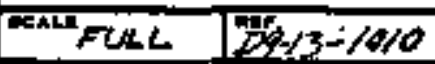 & $\overline{\mathrm{DR} .}$ & Ridnthm & $\sqrt{12-11 \cdot 36}$ \\
\hline & MAVTeEIMLL STFE. & $\pi \boldsymbol{T}$ & & \\
\hline 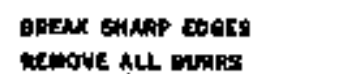 & VLESS STEEL & enk. & 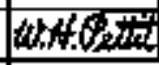 & $40 E C, 13,56$ \\
\hline & TYPE $304 \mathrm{~L}$ LOW & Appr. & & \\
\hline 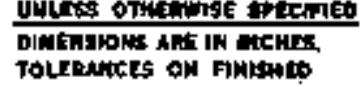 & COBALT & APpet. & Tulg & $z z-\beta-S \mid$ \\
\hline 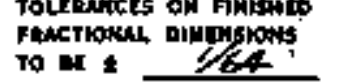 & & MET. & GNQP & 12.28 \\
\hline 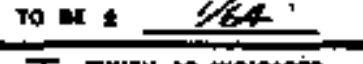 & & $F U$ & $E L E A$ & MENT \\
\hline 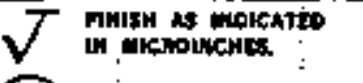 & & $\operatorname{CON}$ & TROK & ROD. \\
\hline & & & & \\
\hline
\end{tabular}

